\title{
UNA INSCRIPCIÓN DE ÉPOCA REPUBLICANA DEDICADA A SALAECVS EN LA REGIÓN MINERA DE CARTHAGO NOVA
}

\section{A ROMAN INSCRIPTION FROM THE REPUBLICAN AGE DEVOTED TO SALAECVS IN THE MINING REGION OF CARTHAGO NOVA}

\author{
RAFAEL GONZÁLEZ FERNÁNDEZ \\ Universidad de Murcia \\ JUAN CARLOS OLIVARES PEDREÑO \\ Universidad de Alicante
}

\section{RESUMEN}

Estudiamos una inscripción votiva inédita procedente de Mina Mercurio (Portmán, Cartagena), depositada en el Museo Arqueológico de Águilas. La dedican unos libertos de la gens Roscia, conocida familia de negotiatores que firmaban los sellos de lingotes de galena argentífera que aparecieron en el Cabezo Rajao de La Unión, en torno a 1846. Se trata de una de las inscripciones más antiguas de la zona de Carthago Noua. Se fecha a finales del siglo II o principios del siglo I a. C., fundamentalmente a partir de la utilización de un nominativo plural arcaico en -es. Está dedicada a $\mathrm{Sa}$ laecus, un apelativo que se relaciona etimológicamente con las aguas y con el mar. Por ello y por el lugar donde apareció, formulamos la hipótesis de que haría alusión al dios romano Neptuno o a una deidad hispánica relacionada con el agua.

\section{ABSTRACT}

In this paper we study an unpublished votive inscription from Mina Mercurio (in Portman, Cartagena), exhibited at the Aguilas Archaeological Museum. It is dedicated by freedmen from the gens Roscia, a well-known family of negotiators who used to sign the argentiferous galena ingot hallmark found in Cabezo Rajao in La Unión around 1846. It is one of the oldest inscriptions found in the area of Carthago Noua, and thus, in the whole Hispania. It is dated at the end of the 2nd century or very beginning of the 1 st century b.c., especially with the use of an archaic plural nominative in -es. It is dedicated to Salaecus, a vocative etymologically related to water and the sea. For this reason and because of the place where it was found, it might refer to the Roman god Neptune or to a Hispanic deity related to water.

PALABRAS CLAVE: Salaecus, gens Roscia, libertos, Carthago Noua, inscripción votiva, época republicana.

KEY WORDS: Salaecus, gens Roscia, freedmen, Carthago Noua, votive inscription, republican age.

\section{INTRODUCCIÓN}

En el mes de mayo de 2009, durante el trabajo de recogida de las inscripciones romanas de la Región de Murcia, ${ }^{1}$ conocimos la existencia de una pieza inédita depositada en el Museo Arqueológico Municipal de Águilas ${ }^{2}$ que fue encontrada, según la información proporcionada por la persona que la donó al museo, cerca de la boca de la Mina Mercurio, situada en la Rambla de la Boltada, en Portmán, y en cuya desembocadura se encuentra la conocida villa romana del Huerto del Paturro. Se trata, sin lugar a dudas, de una pieza extraordinaria que, a pesar de su carácter extremadamente sintético y de su pequeño tamaño, presenta unas características excepcionales de cara al estudio de la primera etapa republicana de Carthago Noua.

La zona del hallazgo se encuentra dentro del llamado distrito minero de La Unión/Cartagena y en él que se distinguen una serie de áreas como son el Cabezo de Sancti Spiritus, los collados de Don Juan,

\footnotetext{
${ }^{1}$ Parte del grupo de investigación de la Universidad de Murcia «Antigüedad y Cristianismo», nos hemos propuesto recoger, clasificar y estudiar todas las inscripciones latinas de época romana de la Región de Murcia, excepción hecha de las de Cartagena que ya han sido publicadas y forman un corpus por sí solas.

${ }^{2}$ Fue donada al Museo Arqueológico Municipal de Águilas en el año 2000, junto con otras piezas, por don Luis Díaz Martínez, sacerdote y, en la actualidad, cronista oficial de Águilas. El número de inventario es MA 624. Queremos agradecer al director de dicho museo, don Juan de Dios Ramírez García su amabilidad y todas las facilidades que nos ha prestado para el estudio de la pieza.
} 
Ponce y El Lirio, el Cabezo Rajao y El Pino. ${ }^{3}$ Para el objeto de nuestro trabajo, la zona que nos interesa es la primera, el Cabezo de Sancti Spiritus, que era uno de los lugares de mayor altitud de la Sierra de Cartagena en la Antigüedad. Debido a lo abrupto del terreno, en la zona se podrían plantear dos problemas fundamentales: la extracción del mineral y su salida hacia las fundiciones y los puertos para su posterior comercialización. En gran medida, la respuesta a estos problemas la dan los yacimientos arqueológicos que jalonan las ramblas y barrancos que son, en definitiva, los únicos accesos al Sancti Spiritus. En este sentido, una de las principales salidas, situada en la vertiente Sur, se hacía a través de las ramblas de La Boltada y de Los Chorrillos, localizadas sobre la bahía de Portmán. Precisamente, la de La Boltada comunica directamente Sancti Spiritus con la bahía de Portmán. A lo largo de esta rambla se encuentran una serie de yacimientos muy significativos: Mina Mercurio, Mina San Ramón, Desembocadura de la Rambla y el Huerto del Paturro, éste último, al final de la rambla, pero fuera de la misma. ${ }^{4}$

Los dos primeros pertenecen a lo que se consideran asentamientos ligados a las actividades extractivas y transformativas del mineral, que están normalmente ubicados en altura, cerca de los pozos extractivos, aunque bien conectados con la red viaria. Presentan en su conjunto una distribución espacial compleja, rodeados por una estructura perimetral, con una clara zonificación funcional ligada con la manufactura del mineral y organizada alrededor de un edificio principal en el que se vislumbra cierta preocupación decorativa. Todos estos factores permiten relacionar estos establecimientos con el control administrativo de los distintos distritos mineros, con la distribución de mercancías y suministros y, además, son utilizados como vivienda. ${ }^{5}$ Estos edificios principales, dotados de cierto grado ornamental, han sido interpretados generalmente como habitaciones de carácter residencial; sin embargo, no se puede descartar que estas construcciones funcionaran como edificios públicos e incluso como santuarios. ${ }^{6}$

Precisamente, estas características son visibles en las instalaciones de Mina Mercurio, donde aparecen habitaciones pavimentadas con losetas de cerámica ${ }^{7}$,

3 Sobre los distritos mineros del sureste y especialmente de los de Cartagena $c f$. Ramallo Asensio; Berrocal Caparrós 1984, 93-103.

${ }^{4}$ Ibid., 95.

${ }^{5}$ Antolinos; Noguera; Soler 2010, 199.

${ }^{6}$ Ibid., 203.

Este pavimento se conserva en el Museo Arqueológico de Portmán. Estaba realizado con losetas cerámicas con forma de escamas de pez o imbricaciones y estaría datado entre pero desgraciadamente no disponemos de más datos, ya que nunca se ha llevado a cabo una excavación sistemática en el lugar.

Muy cerca de la Mina Mercurio, en la Mina San Ramón, fue descubierto a comienzos del siglo xx el conocido epígrafe votivo de Sextus Numisius, ${ }^{8}$ muy cerca de importantes estructuras industriales relacionadas con el procesamiento del mineral extraído en la zona y que incide en la costumbre de ofrecer votos a divinidades tutelares por los encargados o administradores de las minas. ${ }^{9}$

En la llamada Desembocadura de la Rambla se documentaron tres piletas rectangulares revestidas con mortero hidraúlico que, si bien en un primer momento se consideró que su uso había sido destinado a salazón o esparto, ${ }^{10}$ en la actualidad se interpretan como lavaderos de mineral. ${ }^{11}$

Finalmente, junto a la bahía se encuentra el yacimiento del Huerto del Paturro, que conocemos algo mejor debido a las diversas intervenciones arqueológicas que se han desarrollado en sus límites. La villa está enclavada en un lugar estratégico, cerca de las explotaciones metalúrgicas de la Sierra Minera y dispone de un amplio territorio en sus alrededores para su abastecimiento. También existían vías terrestres que conducían hacia la Manga y Cartagena, una de ellas en las proximidades del yacimiento. Pero, con todo, es la cercanía al fondeadero de Portus Magnus lo que contribuiría a favorecer, sin lugar a dudas, los intercambios y la orientación económica de las transformaciones allí realizadas. ${ }^{12}$ Fue descubierto en 1969 y desde entonces se han llevado a cabo varias campañas de excavaciones arqueológicas que han puesto de manifiesto la existencia, en sectores aterrazados de cara al mar, de dos partes bien diferenciadas: una, la señorial o doméstica, en la que vivían los dueños de la villa, de carácter más refinado. En el segundo sector, de carácter industrial, la actividad estaría directamente relacionada con la gestión de recursos hídricos, quizás procedentes del agua de escorrentía del barranco inmediato, derivada desde la plataforma superior del yacimiento hacia las conducciones que la depositan en varias estructuras ya excavadas (balsas) que podrían estar relacionadas con

el s. II y el s. I a. C. Esta técnica de pavimentación en frecuente en contextos arqueológicos de época tardorrepublicana, y suelen aparecer con profusión en ambientes domésticos de numerosas ciudades púnicas del norte de África (Antolinos; Noguera; Soler 2010, 200-202, nota 128).

${ }^{8}$ Abascal; Ramallo 1997, 469-472, no 222; Díaz Ariño 2008, 136, C49.

${ }_{9}$ Antolinos; Noguera; Soler 2010, 215.

${ }^{10}$ Ramallo; Berrocal 1984, 96.

${ }^{11}$ Antolinos; Noguera; Soler 2010, 188.

${ }^{12}$ Lara Vives; López Seguí 2010, 233-234. 
el trabajo de las salazones y/o esparto y que fueron objeto de constantes transformaciones a lo largo de más de un siglo. ${ }^{13}$

La villa del Paturro muestra dos niveles claros y diferentes de ocupación:

- Un primer nivel de época tardorrepublicana. Durante esta época debió ser un asentamiento comercial con una función diferente a la que luego desempeñó. La cercanía a las explotaciones minero-metalúrgicas de la Sierra Minera y la ubicación en la línea de costa, próxima al fondeadero antes citado, no descarta la posibilidad de un asentamiento de tipo comercial, vinculado a las explotaciones mineras, en un primer momento de ocupación entre finales del siglo II y principios del siglo I a. C. $;{ }^{14}$ no obstante, es un riesgo establecer una determinada funcionalidad de la villa en un período caracterizado por la escasez de datos disponibles, máxime cuando el sector A, el de cronología más antigua, no está totalmente excavado. ${ }^{15}$

- Una segunda fase, mejor conocida por el mayor número de datos disponibles nos muestra una villa tal vez dedicada a la transformación de las materias primas provenientes del mar y del amplio campo de cultivo del entorno, es decir, producción de salazón o esparto que, gracias a la localización de la misma, podría haber sido lugar de intercambio o de comercialización. En un momento que no podemos precisar con seguridad, pero que podría tratarse de finales del siglo i d. C., o inicios del siglo II d. C., los restos arquitectónicos y el repertorio ornamental muestran su probable transformación en una villa de carácter residencial. Sus paredes son decoradas con pintura mural, sus suelos pavimentados con mosaicos bícromos, se le dota de unas termas e, incluso, el peristilo debió estar adornado con un importante conjunto escultórico. Tras este periodo de esplendor (ss. I-II d. C.), la villa del Paturro debió sufrir la crisis que también experimentó la ciudad de Cartago Noua, puesto que ya no se encontraron restos arqueológicos fechables en el siglo III d. C.

\section{LA INSCRIPCIÓN}

Se trata de una inscripción votiva de reducidas dimensiones. Está realizada sobre una piedra muy

\footnotetext{
13 Ibid., 237-238.

${ }^{14}$ Fernández Díaz 2008, 361.

${ }^{15}$ Campaniense A, vajilla de producción helenística y un as con Jano bifronte (Ramallo 1985, 78.) Aunque esta opinión no la compartía Méndez que consideraba que la villa podría haberse construido en la segunda mitad del siglo I a.C. (Méndez 1987, 267).
}

porosa, de color gris claro, posiblemente una toba calcárea (travertino), rica en alvéolos que, sin llegar a dificultar la lectura, velan algunos trazos.

La inscripción está sobre la cara rectangular frontal de un bloque paralelepípedo recto, al que se le han alisado las caras, al menos las que conserva sin fracturar (la derecha, la superior y la inferior), por lo que pensamos que todas presentaban ese alisado. Al estar la pieza rota por su parte izquierda y por detrás, desconocemos sus medidas originales, aunque suponemos que en la parte de la izquierda, la más importante ya que es donde comienzan las dos líneas de la inscripción, no se ha perdido mucho.

La longitud conservada de la cara inscrita es de $19,1 \mathrm{~cm}$, la altura total de $6,4 \mathrm{~cm}$ y la profundidad conservada es de 9,4 cm. La altura de las letras de la primera línea varía entre 1,7 y $2 \mathrm{~cm}$. En la segunda línea, lo mismo, entre 1,7 y $2 \mathrm{~cm}$, pero en general, para la media, son algo más bajas que en la primera línea.

El espacio entre las dos líneas es, prácticamente, uniforme: varía apenas $1 \mathrm{~mm}$, entre 0,9 y $1 \mathrm{~cm}$. Entre la parte superior de la pieza y la primera línea hay entre 0,8 y $0,9 \mathrm{~cm}$. Entre la parte inferior y la segunda línea el espacio es menor: varía entre 0,5 y $0,6 \mathrm{~cm}$.

Presenta interpunciones que no son fáciles de ver debido a la calidad de la roca, puesto que es fácil confundirlas con los alveolos. Aún así, tras una atenta observación, se descubren cinco interpunciones, hechas con golpes de cincel. La primera, en el inicio conservado de la primera línea antes de la $\mathrm{M}$ del praenomen, por lo que se puede restituir al menos una letra, que correspondería a otro praenomen. No creemos que se haya perdido más. ${ }^{16}$ Las otras interpunciones de esta línea entre $\mathrm{M}$ y $\mathrm{R}$, entre $\mathrm{S}$ y $\mathrm{M}$, y entre M y L. En la segunda línea sólo aparece un signo separando las dos palabras (entre O y D). Es interesante destacar que antes de la $\mathrm{S}$ de la segunda línea hay suficiente espacio para que, si hubiera habido interpunción, ésta se conservaría, por lo que al no ser así pensamos que la línea está completa. La letra es capital cuadrada de regular factura. Algunas presentan acusados remates, concretamente en la primera línea la $\mathrm{R} S$, C y S del nomen, la última L. En la segunda línea la S, L, E, y C del teónimo, así como E, E y V en la forma verbal final.

\footnotetext{
${ }^{16}$ De hecho, lo habitual en el tipo de plural en -es, que presenta el gentilicio, es que se refiera a dos personas, aunque también existe algún caso con tres. Ernout precisamente hablaba de uso de pseudodual por lo frecuente de esta formación. Cf. nota 29 y para ejemplos nota 27.
} 


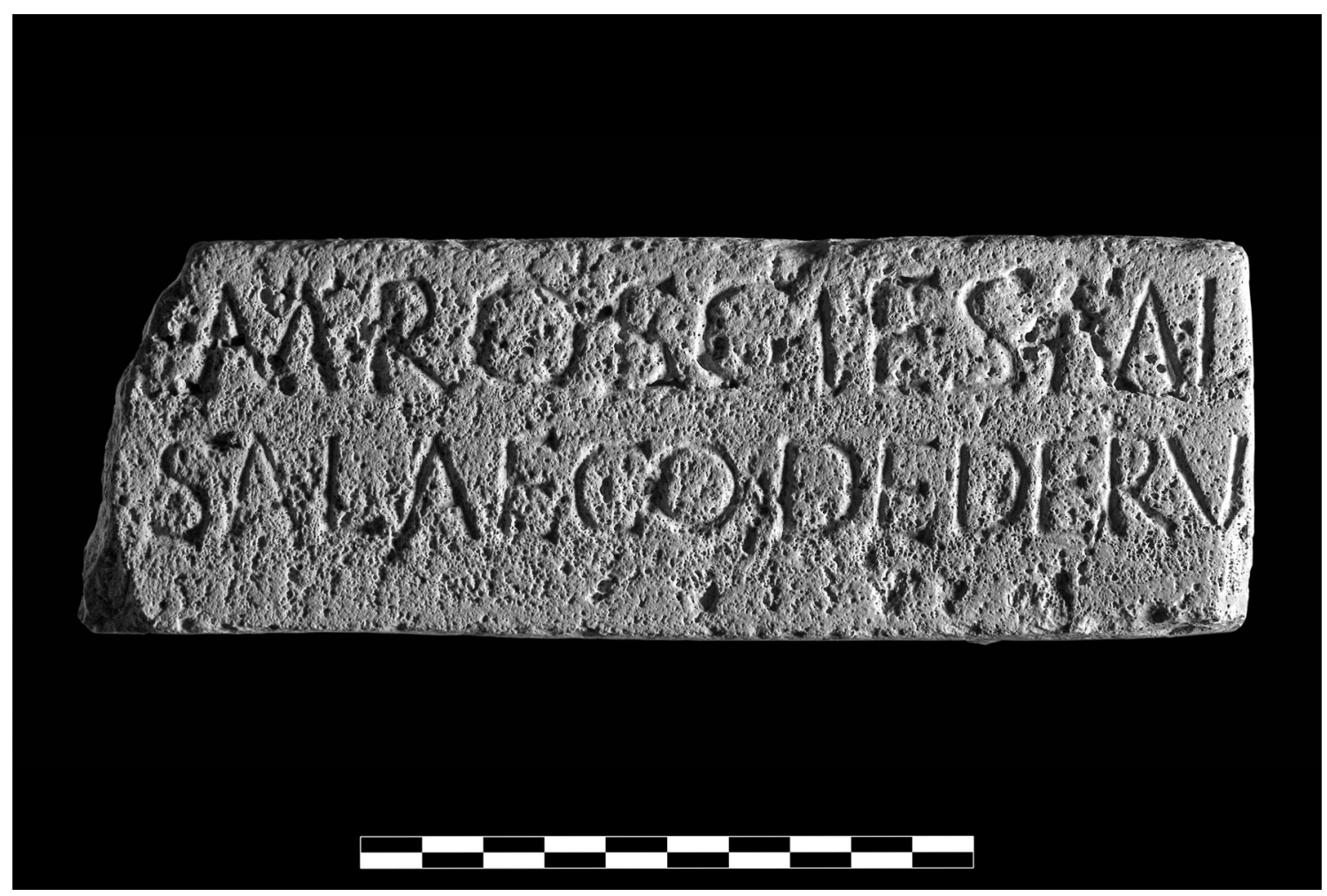

Las dos líneas son:

\section{[-] M(arcus) ROSCIES M(arci) L(iberti) SALAECO DEDERV(nt)}

Traducción:

...y Marco Roscios, libertos de Marco para Salaeco lo ofrendaron

La ausencia de cognomina nos confirma su temprana cronología que, en cualquier caso, viene corroborada por la desinencia del nominativo plural, como ahora veremos.

Respecto a la forma verbal DEDERV(nt) existen paralelos, por supuesto, muy antiguos: ${ }^{17}$ CIL I I 22 (probavero, encontrado en la vía ostiense); 61 (donu [d]edero de Praeneste); 378 (dono dedero, en Pesaro, Umbría); 379 (dono dedro, en Pesaro, Umbría); 2542 (courauru, cerca del templo de Juno Lacinia); 2659 (dedero [do]no, cerca de la orilla del lago Albano).

A pesar de la brevedad de la inscripción, hay dos elementos muy destacables. En primer lugar, un nuevo

${ }^{17}$ Con desaparición de la nasal y caída de la -t final. Cf. Ernout 1966, 28. ejemplo de nominativo plural de la segunda declinación en -es, que nos lleva a fechar la inscripción a finales del II a. C., o muy principios del s. I a. C. En segundo lugar, la aparición de una denominación, hasta ahora desconocida, de un dios, pues así interpretamos el nombre (Salaeco, en dativo) que aparece en la segunda línea, bien sea el propio teónimo o, lo que es más probable, un apelativo de la deidad. La inscripción se cierra con el verbo en plural dederu(nt). Por la posición en la inscripción, interpretamos que sería una divinidad, de la que no poseemos ningún otro testimonio hasta ahora, a la que unos libertos de M. Roscio, un negotiator que ya conocemos por los lingotes de plomo, dedican la ofrenda.

Por tanto, según nuestra interpretación, se trata de dos libertos ${ }^{18}$ de un Marcus Roscius, personaje éste, sin lugar a dudas, relacionado con los dos hermanos de la gens Roscia, ${ }^{19}$ Publio y Marco (podrían ser libertos de éste último), negotiatores romanos vinculados a societates beneficiarias de las concesiones que

${ }^{18}$ Estadísticamente es lo más probable, generalmente este tipo de plural aparece con dos praenomina, el uso llamado pseudodual por Ernout. Cf. nota 23 y 28. Probablemente se trate de un segundo Marco.

19 Solin; Salomies 1988, 157. «Roscius», RE 20.1, 1914, cols. 1116-1128, para los dos hermanos cf. $\mathrm{n}^{\circ} 5$. 
explotaban las importantes minas de galena argentífera de los alrededores de Cartagena. Estos aparecen citados en los sellos de más de treinta lingotes de plomo $^{20}$ encontrados en 1846 en los alrededores de Cartagena, concretamente en el Cabezo Rajado, en Roche $^{21}$ (La Unión ${ }^{22}$ ), con la leyenda en una cartela de 2 x $22 \mathrm{~cm}:{ }^{23}$

\section{M(arcus et) P(ublius) Roscieis M(arci)f(ilii) Maic(ia)}

El lugar del hallazgo está situado en la llanura que se extiende al norte de la sierra minera, donde se han identificado varias fundiciones de plomo y plata con escoriales, en un radio entre 2 y $4 \mathrm{~km}$ al norte y nordeste de Roche (Cabezo Ventura, Cabezo la Atalaya, El Gachero, Lo Rizo, Los Beatos, Las Claras, Los Gallaros). Para Cl. Domergue uno de estos sitios podría haber sido la fundición de los Roscii. ${ }^{24}$

Domergue fecha estos lingotes hacia finales de la República, en concreto entre finales del siglo II a.C. y la primera mitad del siglo i a.C., aunque parece más probable el final del II a. C. Son además los más antiguos, dentro de su clasificación de lingotes tipo I, de los encontrados en Carthago Noua y sus alrededores. Su temprana fecha viene dada por la forma arcaica del nominativo. ${ }^{25}$ Es un gentilicio conocido, sobre todo, en los últimos tiempos de la República y comienzos del Imperio ${ }^{26}$. Estos Roscios que firman los sellos podrían tener un origen probable de

${ }^{20} C I L$ II $3439=C I L$ II $6247,4=C I L \mathrm{I}^{2} 2397=I L S 8706=$ ILLRP 1262. Aunque Dessau en ILS 8706 los hace proceder de unas minas cercanas a Orihuela: (In fodinis antiquis prope Orihuela repertae massae plumbeae plus triginta...). Rickard 1928, 42, posiblemente por seguir a Dessau también los hace proceder del mismo lugar: «Thirty ingots were found in the débris of an ancient smelting works at Orihuela, in Valencia.»

Son lingotes de sección parabólica cuyas dimensiones son variables, pero están en torno a $0,44 \times 0,8 \times 0,10 \mathrm{~m}$ y un peso entre 32 y $34 \mathrm{~kg}$.

${ }^{21}$ «Cerca de los caseríos de Roche, distrito minero de Cartagena, hacia el año 1846», según Rodríguez Berlanga (citado en Domergue 2005, Bocamina, 190). Domergue en el mismo lugar hace notar la proximidad entre las dos palabras, Roscii y Roche.

${ }^{22}$ La Unión se creó como municipio el 1 de enero de 1867, por eso la referencia anterior a Roche pues los lingotes se encontraron antes de la creación del municipio actual.

${ }^{23}$ Una completísima puesta al día bibliográfica sobre estos lingotes se puede encontrar en Abascal y Gimeno 2000, 180. También en Díaz Ariño 2008, 288.

${ }^{24}$ Domergue, Bocamina 2005, 190.

${ }^{25}$ Como paralelos de desinencias arcaicas en inscripciones de finales del siglo II a.C. presenta $C I L \mathrm{I}^{2} 584$, del 117 a.C., $C I L \mathrm{I}^{2}$ 675, 676 y 677 del 108 y 106 a.C. El propio Hübner comentaba (en CIL II 3439) que era incluso anterior a una de las inscripciones consideradas de las más antiguas de Carthago Noua: la CIL 3433, fechada en torno al año 100 a.C.

${ }^{26}$ Cf. $R E$ 20.1, 1914, cols. 1116 ss.
Lanuvium, ${ }^{27}$ y formarían una societas de tipo familiar como otras existentes en la Hispania romana y en otras zonas del Imperio. ${ }^{28}$ Se trataría, por tanto, de dos ciudadanos romanos adscritos a la tribu Maecia: ${ }^{29}$

La relación entre estos hermanos Roscii y L. Roscius Fabatus, legado de César en la Galia en el año 54, pretor en $49,{ }^{30}$ inscritos todos en la tribu Maecia, y sin duda originarios de Lanuvium, no se puede asegurar, pero el hecho debe ser tenido en cuenta. ${ }^{31}$

Su área de dispersión es muy restringida. Tenemos ejemplos en el Lacio, Umbría y entre los volscos. También en Praeneste, Tusculum, Campania y en los peucettis. ${ }^{32}$ Uno de los ejemplos epigráficos ${ }^{33}$ más antiguos es el que hace referencia a D. Roscius $Q$. $l$. Lin[t]io, magister de Capua, fechado en 106 a. C.

El nomen Roscius cuenta con pocos ejemplos en Hispania. ${ }^{34}$ Es un gentilicio de procedencia estrictamente romana, como los Baebios presentes también en Cartagena así como $S$. Lucretius. Los gentilicios de origen itálico son, por supuesto, los más numerosos: L. Aefolanus (campano), C. у M. Aquinus (testimoniado en Campania y Umbría), L. Cervius (volscos, campanos, latinos); C. Fiduius (del sur de Italia); C. Messius (osco), Nona (etrusco); L. Planius (campano); C. Poplicius (Piceno, Campania, Latium, peucettis y volscos); C. Utius (campano).

Sobre el nominativo plural de la segunda declinación en -eis, -is, -es, los ejemplos que tenemos son

\footnotetext{
${ }^{27}$ Domergue 1990, 256, estampilla no 1038, y 321. Así lo admite también Dessau (ILS 8706: Fortasse Lanuvio oriundi erant duo hi Roscii). También podrían proceder de Lanuvium los Turullii, que portan la tribu de este municipio: «The Roscii come from Lanuvium, and perhaps the Turullii, who likewise carry the tribe of that municipium» (cf. Syme, 1964, 124). La gens Turullia es una de las grandes familias de Carthago Noua, bien conocida por las marcas de los lingotes y por la epigrafía. Parece como si los miembros de las potentes gentes de la ciudad frecuentaran el interior de la Península en busca de mano de obra, en este caso agrícola, quizás en otras ocasiones para la producción minera (Koch, 1994, 233-246).

${ }^{28}$ De la zona de Carthago Noua podemos citar, entre otros, a miembros de familias que aparecen en distintas cartelas como los Aquinii, Planii, Atellii, (Domergue 1990, 254 y 265 , $\mathrm{n}^{\circ} 1004, \mathrm{n}^{\mathrm{o}} 1003,1005$ y 1006) y otros atestiguados en una misma cartela como M. (et) Sex. Caluius M.F.(256 y 266, $\mathrm{n}^{\circ}$ $1010) ; S$. et T. Lucretius (256 y265, $\left.\mathrm{n}^{\circ} 1046\right)$ e incluso un caso idéntico al que tratamos, unos libertos $A$. (et) P. Furieis C. (et) P. (et) L. l(iberti) (Pena 1990 1991, 395, no 6).

${ }_{29}$ Sin duda después del 322 a.C.

${ }^{30}$ Caes., Gal. 2,11,13; 4, 22, 5 y 38, 3, etc.,

${ }^{31}$ Domergue 1990, 328.

${ }^{32}$ Conway 1967, 34, 155, 257, 307,343 y 372.

${ }^{33}$ ILLRP 715, CIL I $\mathrm{I}^{2}$ 678, CIL X 3778, ILS 3397.

${ }^{34}$ Abascal 1994, 210-211. CIL II ${ }^{2} / 7,160=$ CIL II 2177, en Montoro (Córdoba); BRAH, 47, 1905, 64-65, nº 66 en Villamesías (Cáceres); CIL II 4970,428 = CIL II 6349,35, en Tarragona; $A E 1991,970=A E 1992,966$, también de Villamesías; IRCP 652.
} 
casi exclusivamente de textos epigráficos de época republicana ${ }^{35}$ y sobre su origen no hay un criterio común. ${ }^{36}$ Se han ofrecido, esencialmente, tres explicaciones, a las que hay que añadir las que suman combinaciones de éstas. ${ }^{37} \mathrm{Y}$ serían las siguientes:

1) $-e(i) s$ como innovación del latín, con una $-s$ añadida a la terminación regular de la declinación temática en - $o$, por analogía con las desinencias de los temas en consonante.

2) Arcaísmo heredado.

3) Influencia dialectal (osco-umbra).

$\mathrm{Si}$ bien es cierto que aparte de la forma magistre $(i)$ s, de frecuente aparición, son las formas nominales de los gentilicios ${ }^{38}$ las que más predominan, ${ }^{39}$ generalmente con dos prenomina (el uso llamado pseudodual por Ernout ${ }^{40}$ ).

De la Península Ibérica se conocen siete ejemplos de estos nominativos plurales en -eis, -is, -es: ${ }^{41}$

1 y 2: la fórmula HEISCE MAGISTRIS de una inscripción de Cartagena, en paradero desconocido: $C I L \mathrm{I}^{2} 2270=C I L$ II $3433=$ Degrassi $777=$ Vives 1299 = Beltrán, $A E A, 1950$, n$^{\circ} 6=$ (Abascal-Rama1lo) ECN 217.

${ }^{35}$ La variante es -is sería algo más tardía. Cf. Vine, 1993, 215. Según Bakkum 1994, 19-39, especialmente 19-20, estos nominativos se dan desde el siglo III a. C. hasta la primera mitad del s. I a.C. y aunque aparecen como formas pronominales en textos literarios, los nombres (en forma de gentilicios, profesiones, cargos públicos, o términos específicos como magister, etc.) son exclusivos de la epigrafía.

${ }^{36}$ Sobre estos nominativos véase Carnoy 1906, 229-230; Ernout 1905-1906, 293-349, concretamente pp. 344-346; id. $1953^{3}$, 31; Kent 1912, 35-56. Sommer 1914, 346; Devoto 1940, 192-193; Monteil 1953³ , 164; Jiménez Zamudio 1988a, 105-110; id. 1988b, 121-126; Pena 1990-1991, 389-400. Los últimos estados de la cuestión pueden verse en Vine 1993 especialmente 216-239. Barreda Pascual 1995, 49-65. Beltrán 1999,65 , con un resumen sobre las distintas posturas acerca de la procedencia de esta hipercaracterización.

${ }^{37}$ Entre las soluciones de compromiso destaca la de Coleman 1990, 1-25, especialmente 9 ss., ya que piensa tanto en una influencia analógica como de la lengua osca.

${ }^{38}$ Vine, 1993, 218 presenta una lista de nomina (la gran mayoría se refieren a dos personajes) todos en CIL $\mathrm{I}^{2}$ : Q.M. Minucieis 584; Sex Q. Vesuies 993; L.L. Alfieis 1236; M. P. Vertuleieis 1531; P.L. Freis, 1612; L.P. Modies 1850; L.L. Orbieis 2252; C.L. Tossieis 2323; M. P. Roscieis 2397; Cn. M. Vinucieis, 2541a; en Appendix nummorum: L.C. Memies 269; L.L. Caecileis 3004b (cf. 3004a [L.L. C]aecileis); L. P. Sp(e)dies 3425. Las secuencias de tres individuos son mucho más raras: $C n$. Cn. Cn. Septumieis 1382; P.Ti.Sex. Herennieis 1814. Existen algunos ejemplos incompletos en los que no se ha podido determinar el número: ]Popilies [, 3061; Valerieis, 3488; Sertorieis, Epigraphica 45, 1983, 130 ss.

${ }^{39}$ Ocasionalmente se han encontrado cognomina $\left(C I L \mathrm{I}^{2}\right.$ 584 (Sent. Minuc.) Rufeis; 1469 Pontanes. O referencias a grupos: CIL I ${ }^{2} 584$ (Sent. Minuc.) Vituries/Veituris, Cavaturine $(i)$ s, Mentovines.

${ }^{40}$ Ernout 1905-1906, 344-346.

${ }^{41}$ En la descripción de los ejemplos seguimos a Pena 1990 1991, 389-400.
3: la misma fórmula que aparece en un mosaico en signinum en Mazarrón: ${ }^{42}$ HEISCE MAG.

4: línea 16 del bronce de Contrebia Belaisca, ${ }^{43} \mathrm{del}$ año 87 a.C.: (MAG)IS(T)RATVS CONTREBIENSES HEISCE FUERUNT.

5: los lingotes de plomo del Cabezo Rajado (La Unión, Murcia): M. P. ROSCIEIS M. F. MAIC

6: lingote hallado en el mar, cerca de Marsella, ${ }^{44}$ con la estampilla A.P. FURIEIS C.P.L.L., cuya lectura es: A(ulus) (et) P(ublius) FVRIEIS C(aii) (et) $P($ ublii) (et) L(ucii) L(iberti). La cronología es anterior a los años 105-102 a. C.

7: En la última línea del bronce de Alcántara ${ }^{45}$ (104 a.C.) se lee: $C R E N(O$ ?) (ET?) ARCO CANTONI F LEGATES.

El ejemplo que nosotros presentamos sería el octavo y se suma a los de Cartagena y su entorno. Vemos, por tanto, que para los hallazgos hasta hoy conocidos, la dispersión es muy restringida. Se limitan a la zona de Cartagena, además de otros dos ejemplos de documentos jurídicos en Aragón y Extremadura. La cronología de todos ellos va desde finales del s. II a. C. a inicios del I a. C. En resumen, son cinco formas en -eis: tres veces heisce (dos en Carthago Noua y una en el bronce de Contrebia); los nomina Roscieis, de Carthago Noua y Furieis, aparecido en la costa de Marsella, pero que comerciaban con metal de Cartagena. Una única forma en -es (legates), en el bronce de Alcántara. Por último, la que se incorpora con nuestro estudio, una nueva forma en es (Roscies) del entorno de Carthago Noua.

En Italia existen diversos testimonios epigráficos en los que se pueden ver nominativos de este tipo, especialmente en el Lacio, en torno a Roma, en Tíbur, Cora, Sora y al sur, en Capua y Benevento, hasta la costa adriática, en Ariminium ${ }^{46}$, con un arco cronológico que va de finales del s. III a. C. hasta el s. I d. C. Sin embargo, fuera de Italia, aparte de los ejemplos hispánicos citados, sólo disponemos de otras dos evidencias de estas formas, una en Delos ${ }^{47}$ zona con importante presencia sabélica, y otra, la llamada sen-

${ }^{42}$ Ramallo 1979-80, 287-317; id. 1986, 183-187; Id. 1985, pp. 79-82.

${ }^{43}$ Fatás 1980; Mariner 1981, 67-94.

${ }^{44}$ Liou 1991, 15-19. Se trataría de dos libertos de tres hermanos que sellan unos lingotes que por su forma, peso y tipo de estampilla se puede afirmar que proceden de la zona de Cartagena.

${ }^{45}$ López Melero et al. 1984, 265-323.

${ }^{46}$ Algunos ejemplos pueden verse en Jiménez Zamudio 1988b, 121.

${ }^{47}$ Una serie de inscripciones bilingües en las que aparece la fórmula heisce magistreis/-es: Degrassi, ILLRP, núms. 747-762; Roussel; Launey 1937, núms. 1731, 1732, 1733, 1753 y 1754. 
tentia Minuciorum $\left(\right.$ CIL I ${ }^{2}, 584=$ Degrassi, 517), datada en 117 a. C. ${ }^{48}$

\section{LOS DEDICANTES}

El hallazgo de este epígrafe supone un ejemplo más de la antigüedad del corpus epigráfico y del protagonismo de los libertos en la epigrafía de Carthago Noua, donde ejercieron un papel director no sólo en la economía sino también en la cultura. Este estuvo marcado, sobre todo, por la explotación minera y metalúrgica, lo que dio un carácter especial a la ciudad frente, por ejemplo, a otros puertos importantes del Mediterráneo occidental como Tarraco (más relacionado con la presencia de tropas más o menos estables o de paso), o Narbo Martius, ${ }^{49}$ con intereses económicos algo distintos a los de Cartagena.

En los lingotes hallados en minas, en el entorno de Cartagena o en pecios están atestiguadas más de una decena de familias itálicas que se dedicaban y controlarían, en alguna medida, la actividad minera de toda la zona del Sureste: ${ }^{50} \operatorname{los}$ Messii, Planii, Atellii, Turullii, Aquinii, Pontilieni, etc. Concretamente en los plomos, en algunos casos encontramos a varios miembros de una misma familia e incluso durante generaciones; así miembros de la familia Aquinia en abundantes plomos. ${ }^{51}$ Hay también varios Laetilii y Planii, así como varias generaciones de Atellii. ${ }^{52}$ Asimismo se ha podido confirmar el origen itálico de algunas familias: Aquinus es frecuente en Campania y Umbría; Messius entre los oscos; Nona en Etruria; Planius y Utius también en Campania.

A. Marín ${ }^{53}$ propone que estos itálicos fueron los auténticos protagonistas de la migración civil y económica. Considera que nombres como Balbus, Roscius, Lucretius, o Cornelius deben relacionarse más bien con clientelas provinciales que dieron lugar a nuevas aristocracias locales. Aparecen además ciudadanos romanos con mención de tribu: P. Turullius, M. y $P$. Roscieis pertenecen a la tribu Maecia; $C$. Utius, Cn. Atellius y $Q$. Seius a la Menenia y $C$. Pontilienus a la Fabia (los de Cartagena estaban adscritos a la Sergia y a la Galeria).

En el caso que nos ocupa hay un paralelismo claro con los Aquinios, negotiatores, cuyo liberto Marco Aquinio Andro construye un pequeño templo en el cabezo del Gallufo en la zona de Santa Lucía, en

\footnotetext{
48 Pena 1990 1991, 399.

${ }^{49}$ Pena 2002, 47-62; id., 2008, 687-710, espec. 703-704.

${ }^{50}$ Rodríguez et al. 1999, 228.

${ }^{51}$ González Fernández 1995, 351-356.
}

Cartagena, con un pavimento de signinum en el que hay una inscripción musivaria dedicada a Iuppiter Stator $^{54}$ también de finales del II a. C. o principios del i a. C. En el caso de los libertos de Marco Roscio la ofrenda parece más humilde, ya que sólo conocemos esta basa o dintel, en cualquier caso el soporte es muy pequeño, pero el paralelo en cuanto libertos de negotiatores itálicos con dedicatorias votivas es análogo.

Tanto los Aquinios como los Roscios formaban parte de las elites dedicadas al negocio de los metales y su explotación. En este ámbito minero existen dos posibilidades para explicar su presencia: o bien actuaron como agentes de sus patronos itálicos que no llegaron a abandonar su lugar de origen, o bien se quedaron en Cartago Noua en una segunda generación tras el regreso de los itálicos, que dejarían sus negocios en manos de estos libertos. ${ }^{55}$ Estas responsabilidades, además, les darían la posibilidad de abandonar el estado servil y contribuirían a su promoción ciudadana. Garnsey estudia y destaca el papel de los libertos en los sectores no agrícolas de la economía romana en los que podían llegar a formar notables fortunas bien formando parte de sociedades, bien como agentes de sus patronos o mediante iniciativas de carácter independiente. ${ }^{56}$ Podría ser el caso de $C n$. Atellius Bulio y M. Laetitius, de Marco Aquinio Andro o de los Marcos Roscios, protagonistas de este trabajo.

Además, algunas de estas familias que se dedicaron a la actividad minera, pasaron más tarde a ocupar puestos de responsabilidad en el gobierno de la ciudad desempeñando algunas magistraturas sobre todo a partir de Augusto y durante el reinado de Tiberio y Calígula. Michael $\operatorname{Koch}^{57}$ destaca cinco familias que dejaron su testimonio durante varias generaciones tanto en lingotes de plomo como en las leyendas monetarias y en la numerosa epigrafía de la ciudad. Se trata de los Atellii, Aquinii, Laetilii, Turullii y Varii. Si bien es verdad que las inscripciones relativas a magistraturas locales no son muy numerosas y entre las que conservamos hay nomina que no aparecen en las cartelas de los lingotes ${ }^{58}$. Volviendo a los Roscios conocemos su presencia a finales del II, pero no sabemos si en un momento determinado abandonarían la zona o simplemente no tenemos

\footnotetext{
52 Kock 1988, 403-407.

${ }^{5}$ Marín Díaz 1988, passim.

${ }^{54}$ Amante et al. 1995, 533-562; Martín et al. 1996, 26-35.

55 Rodríguez et al. 1999, 229.

${ }^{56}$ Garnsey 1981, 359-371.

${ }^{57}$ Koch 1988, 403-407.

${ }^{58}$ Rodríguez et al. 1999, 230.
} 
constancia de si la familia, a partir de los libertos, permanecería en Cartagena, como es patente en el caso de los Aquinios.

\section{SALAECVS EN EL ENTORNO DE CARTHAGO NOVA}

En cuanto al nombre con que se alude a la deidad, Salaecus, debemos plantearnos, como punto de partida, si el territorio de culto original del dios estaba en torno a la zona donde se halló la inscripción o si, por el contrario, pudo ser un culto extranjero llegado a la región de Carthago Noua. Ello es fundamental para poder calibrar en su justa medida la importancia religiosa y cultural que tuvo la presencia de esta deidad en el entorno de Carthago Noua.

Teniendo en cuenta que esta inscripción religiosa se realizó en el ámbito minero que rodeaba Mina Mercurio y que la dedicación se realizó por unos conliberti y era, por tanto, una dedicación no individual ni, en principio, familiar, hemos de pensar que el culto a la deidad se llevaba a cabo de manera pública y no en un ámbito privado. Unido a este dato, otro elemento nos induce a pensar en la existencia de un lugar sacro dedicado a la divinidad citada. Salaecus es un apelativo cuyo teónimo se omite. La omisión de los teónimos en las inscripciones votivas es, habitualmente, un indicador de que la ofrenda estaba expuesta en el propio santuario del dios, lo que hacía innecesario precisar su nombre ${ }^{59}$ En todo caso, debería haber estado instalada en un lugar donde dicho apelativo hubiera sido suficientemente conocido. Existen varios ejemplos de apelativos citados sin teónimo en aras ubicadas en recintos sagrados de Hispania, que deberían estar bajo la advocación de determinadas deidades. Sabemos que debían estar en santuarios porque se hallaron varias ofrendas en el mismo lugar hechas por devotos diferentes. Así, tenemos varias dedicaciones a Apuluseaecus en alusión a Bandua en Brozas (Cáceres); ${ }^{60}$ a Laroucus, apelativo de Reue en Vilar de Perdices (Montalegre, VilaReal); ${ }^{61}$ a Bormanicus en Caldas de Vizela (Gimarães, Braga), cuyo teónimo es desconocido ${ }^{62} \mathrm{y}$, finalmen-

\footnotetext{
${ }^{59}$ Encarnação (1985-1986, passim.) se refería, principalmente, a aquellas denominaciones donde sólo aparecía una denominación genérica, como Deae Sanctae, Deae Dominae, etc. No obstante, esta hipótesis también sería aplicable a las ofrendas donde sólo se cita el apelativo.

${ }^{60}$ CIL II 741; Salas; Esteban; Rueda (1986-89, 11 ss.).

${ }^{61}$ En cuanto a la primera ofrenda a Reue Larouco sin teónimo, Alves 1909, 351-352; id. 1931, 44-45; Vasconcelos 1917, 16-17. Sobre la segunda, uid. Lourenço 1980, 7-8.

${ }^{62}$ CIL II 2402; CIL II 2403 y 5558.
}

te, a las Duillae en Palencia, que probablemente es un epíteto de las Matres. ${ }^{63}$

Si se acepta que la ofrenda debió estar expuesta en un ámbito público, al alcance de cierta parte de la población minera, es necesario concluir que el dios tenía un colectivo, aunque indeterminado, de adorantes, puesto que hacer una exposición pública de piedad y devoción a una deidad desconocida por el resto de los habitantes, era algo inapropiado en época romana y carecía de todo sentido. La piedad individual por los dioses del conjunto de la población era un valor importante a nivel social y, por ello, se exponía ante los demás y se hacia gala de ello incluyendo el nombre de los dedicantes en las inscripciones, en ocasiones sus profesiones u otros elementos identificativos de los mismos.

En este sentido, si la región de Carthago Noua no hubiera sido una región receptora de inmigrantes a gran escala, tendríamos que concluir que Salaecus habría sido una deidad de la zona. Hay que tener en cuenta que el culto público a una deidad no se transmite entre ámbitos lejanos, según los datos de que disponemos hasta el momento, mediante migraciones individuales. Este tipo de desplazamientos individuales sólo permite transmisiones privadas del culto. Para que un culto se transmita de manera colectiva es necesario que existan desplazamientos de población de cierta entidad, como los generados por movimientos del ejército, ${ }^{64}$ por guerras, deportaciones y confiscaciones de tierras, ${ }^{65}$ por tráfico de esclavos o por migraciones masivas de carácter económico. ${ }^{66}$ Estos últimos movimientos de población, en las provincias hispanas, se produjeron mayoritariamente hacia las explotaciones mineras. ${ }^{67}$

Por tanto, teniendo en cuenta las premisas citadas y la gran cantidad de obreros que se necesitaban para los trabajos mineros, no es probable que Salaecus fuera una deidad autóctona. Es del todo posible que fuera una deidad llegada desde algún punto de Hispania o de cualquier lugar del Mediterráneo, siempre que se trate de un ámbito desde el que llegaran también contingentes de población apreciables, esclavos o población libre, relacionados con las minas. Dado que no tenemos información sobre la procedencia geográfica de los dedicantes de la ofrenda a $\mathrm{Sa}$ laecus, por no aparecer citados sus cognomina, sólo podemos recurrir a información indirecta para conocer

\footnotetext{
${ }^{63}$ Beltrán; Díaz 2007, 32-34.

${ }^{64}$ Cumont 1987, 34; Bemónt 1981, 69 ss.; Birley 1986, passim.

65 Olivares Pedreño 2003, 306-308.

${ }^{66}$ Cumont 1987, 33. Respecto a Hispania, uid. Haley 1986, 380-381 y 401; Olivares Pedreño 2003, 306 ss.

${ }^{67}$ Haley, ibid., loc.cit.; Olivares Pedreño 2007, 144 ss.
} 
su origen: las relaciones comerciales de Carthago Noua con otros ámbitos mediterráneos y la procedencia de otros cultos en la ciudad y su entorno que nos vislumbren cualquier posible migración o traslado de poblaciones hacia las regiones mineras del sureste de Hispania Citerior.

\section{MIGRACIONES ECONÓMICAS A LAS MINAS DE CARTHAGO NOVA Y DIFUSIÓN RELIGIOSA}

Como hemos analizado arriba, entre los individuos que figuran como negotiatores en los lingotes de plomo en el entorno de Cartagena, se encuentra la mayor proporción de individuos que proceden de la Italia centro-meridional (el Lacio y la Campania). ${ }^{68}$ En cuanto a los trabajadores, sabemos por Polibio, quien estuvo en Carthago Noua en el año 151 a. C., que el territorio minero distaba de la ciudad unos veinte estadios y se extendía a lo largo de cuatrocientos, donde se mantenían cuarenta mil trabajadores fijos que reportaban al Estado romano veinticinco mil dracmas diarias. ${ }^{69}$ Gran parte de estos mineros debían ser esclavos que estaban dirigidos por capataces que controlaban las explotaciones. ${ }^{70}$

Según Domergue, parte de estos contingentes de obreros pudieron haber sido también apresados en la Península Ibérica durante las guerras de conquista romanas, lo que se evidencia en los nombres de algunos libertos que aparecen en la epigrafía cartagenera de finales de la República. Varios de éstos tienen los mismos gentilicios, como ya vimos, que algunos propietarios de minas de los alrededores que aparecen en los lingotes de plomo de finales del in y principios del I a. C., mientras que sus cognomina son de origen ibérico, como Samalo o Toloco ${ }^{71}$. También un liberto propietario de una explotación minera, $C n$. Atellius Bullio podría tener un origen paleohispánico y, quizá, terminó dirigiendo una explotación después de años como esclavo trabajando en las minas. ${ }^{72}$

Otros libertos tienen cognomina de origen griego, aunque esto no es un indicio seguro de su procedencia helena. En cambio, libertos como Laetilia

\footnotetext{
${ }^{68}$ Domergue 1990, 322; Brunt 1971, 210 ss.; Abascal; Ramallo 1997,16 y 41 .

${ }^{69}$ Apud Str., 3, 2, 10

${ }^{70}$ Diod. Síc., 5, 36, 3. Vid. Domergue 1990, 336. Para el análisis de esta cuestión, uid. supra.

${ }^{71}$ Domergue, ibid., loc. cit., 324-325 y 336, con tabla XIV. No obstante, estos ejemplos son de finales del s. I a.C., ya en época augustea. Sobre su distribución geográfica, uid. Abascal, 1994,495 y 530.

${ }^{72}$ Domergue, ibid., 325.
}

Marta y M. Laetilius Priamus deberían tener origen sirio u oriental, quizá llegados a Carthago Noua por mediación del mercado de esclavos de Delos. ${ }^{73}$ Como vimos arriba, a finales del siglo II y principios del I a. C. llegaba a las minas del sureste peninsular el mayor número de trabajadores de origen extra-hispano, al contrario que a fines de la República y durante el Alto Imperio, cuando la población hispana será mayoritaria entre los empleados de las explotaciones mineras. ${ }^{74}$ Sabemos, en definitiva, que los negotiatores son, principalmente, itálicos, pero tenemos pocos datos sobre el origen de los libertos que gestionaban las explotaciones y sobre el conjunto de los trabajadores de extracción servil.

No obstante, también podemos considerar los demás cultos desarrollados en la región durante las últimas décadas del s. II y las primeras del i a. C. para vislumbrar de modo indirecto el origen de los flujos culturales que llegaban al sureste de Hispania. En este sentido, son muy reveladores los santuarios dedicados a Iuppiter Stator, citado arriba, y a la diosa Atargatis en Carthago Nova. El primero es una consecuencia de la afluencia de poblaciones centro y suritálicas al sureste hispano, puesto que este culto es, según los datos disponibles hasta el momento, específico del Lacio. ${ }^{75}$ El segundo es un ejemplo de la llegada de grupos, militares, comerciantes, libertos o esclavos, desde el oriente mediterráneo hacia Occidente probablemente, como ya hemos mencionado, con la intermediación del gran centro económico que era la isla de Delos. ${ }^{76}$

\section{ETIMOLOGÍA DE SALAECVS. TOPÓNIMOS RELACIONADOS CON EL APELATIVO RELIGIOSO}

El significado del nombre Salaecus contiene la raíz *Sal-, que pertenece al repertorio hidronímico preindoeuropeo, con el significado de sal, agua sa-

\footnotetext{
${ }^{73}$ Ibid., 336. En cuanto a la relación del comercio de esclavos con el del vino y la llegada a Carthago Nova de esclavos orientales, uid., Molina Vidal 1999, 521 ss. y Ramallo et al. 2008, 591 .

${ }^{74}$ Domergue 1990, 365.

${ }^{75}$ Amante et al. 1995, 560 ss.; Noguera Celdrán 2002, 5153; Ramallo et al. 2008, 583.

${ }^{76}$ Ramallo; Ruiz 1994, 87 ss. y 101; Noguera Celdrán 2002, 52. Pena plantea la posibilidad de que también se mencione a Adad en el texto musivo, lo que incrementaría el valor de este testimonio como apoyo a la idea de la llegada de grandes contingentes de población desde oriente a Carthago Nova, puesto que sería el primer testimonio del dios en el Occidente mediterráneo $(2008,695-697)$. Las ofrendas a Serapis e Isis refuerzan esta idea, aunque puedan ser de época posterior (Abascal; Ramallo 1997, 164-167, n n 37 y 38).
} 
lada, mar o, incluso, corriente de agua. ${ }^{77}$ En este sentido, dicho radical está presente en cuantiosos hidrónimos de la Europa central ${ }^{78}$ y también en la Península Ibérica conocemos un buen número de ejemplos. ${ }^{79}$

El radical *Sal- está también presente en diversos nombres de localidades hispanas: Salacia (*Sal$a k-i a)$, correspondiente a Alcacer do Sal (Setúbal); ${ }^{80}$ en otra localidad del mismo nombre situada en la vía de Bracara Augusta hacia Asturica Augusta, cerca de la primera; ${ }^{81}$ Sala, de ubicación desconocida hasta el momento ${ }^{82}$; Saelini, etnónimo astur citado sólo por Ptolomeo que se situaría cerca del río Sella, denominado Salia en la Antigüedad; ${ }^{83}$ Salaeni, citado por Mela entre los Cántabros en las cercanías del río Saja ${ }^{84}$ Salientes, enclave citado en el Itinerario de Antonino como una mansio de la vía XVIII, quizá situado en Baños de Molgas (Orense); ${ }^{85}$ Salica, mencionado por Ptolomeo en la parte oriental de la Meseta Sur española; ${ }^{86}$ Salmantica (Salamanca) ${ }^{87}$ y Sa-

\footnotetext{
77 Dauzat et al. 1978, 81; García Alonso 2003, 295. Las formas en griego óÜêiò o óÜëç aparecen en distintos autores antiguos con la idea general de mar tormentoso (Trumper $2004,48)$, con todas las referencias literarias. Sobre el término latino salum (alta mar), uid. infra.

78 Algunos ejemplos citados por Dauzat et al. (ibid., loc.cit.) son los ríos franceses Sal (Sale), Salembre (Salambra 1104), Sauldre (Salera 1064), Salaison (Salaronis 1295), Saleron (Salaronis 914), Sallanche (Salanchia 1178), Salat, Salesse, Salice, Saleis (Saleis 1448), Salendre, Saliouse, Sauldron, Salabert, Salagou (Salasco 879), Sale o Saleine (Sealena 1460), Sals (Salz, Salade 1594). También tenemos ejemplos en Britania como Sale (Hogan, 1910, 591). No obstante, también existen numerosos orónimos europeos que contienen esta raíz, como Salarous, Salassous (1.325 $\mathrm{m}$ ), Salenton (dos casos: 2.526 y $2.671 \mathrm{~m}$ ), Saléon, Salers $(951 \mathrm{~m})$, Salèse $(2.031 \mathrm{~m})$, Solaise $(2.551 \mathrm{~m})$, Salettes $(2.709 \mathrm{~m})$, Salève $(1.380 \mathrm{~m})$ y Salier (Dauzat et al., 1978 , 208).

${ }^{79}$ De Hoz $(1963,237)$ aporta los siguientes ejemplos: Salle (Salia en Mela, 3, 14), Salas, Jalón (Salo en Marcial 1, 49), Sela (1322), Selio (926), Selmo, Sellent, Salor, Selir (1257), Selarmir, Seliolo, Salabor (1187) y Salsum. También se pueden añadir el Sal y el Salcera, en Cantabria (Peralta $2000,42)$. En cuanto al hidrónimo Salmantia como origen del topónimo Salamanca, uid. De Hoz 1963, 239; Melena 1985, 524; García Alonso 1992, 195.

${ }^{80}$ García Alonso 2003, 87.

${ }^{81} A E$ 1921, 9; $A E$ 1924, 62

82 Ptol., 2, 4, 9; García Alonso 2003, 51; Curchin 2008, 24, quien la hace derivar de *Sal- (sal).

83 Ptol., II, 6, 33; Tranoy, 1981, 50-51; García Alonso 2003, 226. También se cita un Saelenus en una inscripción aparecida al este de la provincia de Orense (CIL II, 2599), aunque es sabido que no se puede asegurar una identificación entre la origo citado en la inscripción con el lugar de aparición del monumento. El nombre del río Salia es citado por Mela (3, 14).

${ }^{84}$ Mela, 3, 15; Tranoy 1981, 50-51.

85 TIR K-29, 1991, 92.

${ }^{86}$ Ptol., 2, 6, 58; García Alonso 2003, 347.

${ }^{87}$ García Alonso 2003, 120, con bibliografía.
}

lionca, quizá ubicada en Poza de la Sal (Burgos), ${ }^{88}$ donde hay una mina salina, lo que facilitaría la interpretación del topónimo como derivación del radical indoeuropeo *Sal- sal. ${ }^{89}$ El topónimo Salaria, perteneciente al conuentus Carthaginensis y posiblemente situado junto a Ubeda la Vieja (Jaén), correspondía a una colonia romana por lo que, según García Alonso, habría que considerarlo una denominación puramente latina, aun sin desechar plenamente que pudiera pertenecer al repertorio antiguo europeo..$^{90}$

Sin embargo, topónimos derivados de esa raíz no existían sólo en Hispania, ya que también conocemos algunas ciudades en el continente africano que podrían justificar la procedencia de Salaecus como deidad tutelar de las mismas. Sala era una ciudad mauritana situada a $3 \mathrm{~km}$ del estuario del Bou Regreg, río que tenía el mismo nombre que la localidad. ${ }^{91}$ En la actualidad se denomina a la ciudad Šella (Chellah) y está situada a $2 \mathrm{~km}$ de Rabat. El nombre Sala tendría origen fenopúnico y significaría roquedo. Su función portuaria fue lo que otorgó la mayor importancia a la ciudad, puesto que es el único puerto sobradamente protegido de la costa tingitana desde Lixus hacia el sur. ${ }^{92}$ A finales del i a. C., acuñó moneda con la leyenda neopúnica $S$ 'lt. Fue ocupada por los romanos durante el principado de Claudio, llegando a ser municipio en época de Trajano y, posteriormente, fue convertida en colonia según el Itinerario de Antonino $(6,4)$, que la llama Sala colonia. ${ }^{93}$ Aunque varios autores le adjudican un origen fenicio, los niveles más antiguos y fiables son, hasta la fecha, del s. II a. C. ${ }^{94}$

La facilidad del comercio que ofrecía su puerto motivó que llegara a Sala más vajilla importada y ánforas que a los demás enclaves mauritanos, algo claramente constatable desde época de Augusto, que mostraban el dinamismo de un comercio pujante con la Península Itálica y la Bética. ${ }^{95}$

La divinidad más importante de Sala pudo ser la que se representó en sus monedas, que mostraban un

${ }^{88}$ Ptol., 2, 6, 52; TIR K-30, 195; García Alonso 2003, 294; Santos et al., $(1992,458)$ la ubicaban en el Cerro del Milagro de Poza de la Sal.

${ }^{89}$ Curchin 2008, 24.

${ }^{90}$ Plin., nat., 3, 25; Ptol., 2, 6, 58; 2, 6, 60; CIL II 5093; García Alonso 2003, 344; Sobre las menciones epigráficas del caracter colonial de Salaria, uid. Abascal 1996, 65 ss. y Gimeno 2004-2005, passim.

${ }^{91}$ Mela, 3, 107; Plin., Nat., V, 5, 9 y 13; Ptol., IV, 1,2; 6,2; Sobre el río Salex, uid. Philostr., VA, 5, 1: ÓÜëçî.

${ }_{92}$ Ouazghari 2005. Para Trumper, el nombre podría tener un origen griego, con base en *Salo- agua $(2004,47)$.

${ }^{93}$ Lipiñski 1992, 385; López Pardo 1996, 127.

${ }^{94}$ López Pardo ibid., 260.

${ }^{95}$ Ibid., 125-126. 
rostro con barba puntiaguda y largos cabellos que podría ser una deidad políada. ${ }^{96}$ Asimismo, son relevantes sus tres templos, uno de ellos fechable a mediados del s. I a. C., pero cuya advocación se desconoce. ${ }^{97}$

En Africa Proconsular también está testimoniada una ciudad cuyo nombre tiene una directa relación formal con el teónimo Salaecus. Se trata de Salae$c a$, citada por Tito Livio en el contexto de la conquista de Utica por el ejército de Escipión en el 203 a.C. y situada, aproximadamente, a quince millas al oeste de esa ciudad..$^{98}$ Salaeca fue, en principio, ocupada por la caballería cartaginesa al mando de Hannón, mientras las tropas romanas estaban acampadas a una milla de Utica. Escipión, con la ayuda de las tropas númidas encabezadas por Masinisa, provocó que los cartagineses que habían tomado Salaeca salieran de la ciudad a luchar en campo abierto, donde fueron vencidos. Hannón fue muerto y, en la desbandada de sus soldados, los romanos cogieron o dieron muerte a centenares de jinetes. Una vez conquistada Salae$c a$, Escipión dejó una importante guarnición en la ciudad y continuó avanzando con su ejército para preparar la batalla de Utica. ${ }^{99}$

Salaeca, ubicada posiblemente en el actual Henchir-el-Bey ${ }^{100}$, no vuelve a aparecer en las fuentes antiguas desde esos acontecimientos pero, dado que fue controlada con una fuerte guarnición romana, cabe pensar que no fue totalmente asolada, a pesar de la muerte de gran parte de su población y la destrucción de muchos de sus campos y haciendas. ${ }^{101}$

\section{SENTIDO RELIGIOSO DEL APELATIVO SALAECVS. SALACIA Y DIVINIDADES MARÍTIMAS EN EL MEDITERRÁNEO OCCIDENTAL}

Dada la naturaleza del radical *Sal-, también forma parte de nombres de divinidades. Así, aunque en un ámbito cultural muy distinto y escasamente vinculado a Carthago Noua, en la parte occidental de la Península Ibérica que estaba ocupada por pueblos

\footnotetext{
${ }^{96}$ Ibid., 234.

${ }^{97}$ Ibid., 245.

${ }_{98}$ Liv., 29, 34, 6 y 35, 4. Scullard 1929, 192 ss.

${ }^{99}$ Liv., 35, 4. Apiano transmite datos diferentes, por ejemplo, aduciendo que Hannón fue hecho prisionero y canjeado por la madre de Masinisa (App., Lib., 14).

${ }^{100}$ Lancel 1999, 165. Apiano precisa el lugar los acontecimientos cerca de una torre construida por Agatocles (Lib., 14).

${ }^{101}$ Liv., 29, 35, 4-6; App., Lib., 15. Sin embargo, Salaeca pudo cambiar de nombre posteriormente (Hoyos 2007, 101102).
}

lusitanos y vetones, conocemos otro teónimo que podría estar relacionado etimológicamente con Salaecus: Salamati (dat.), que aparece en dos inscripciones procedentes del Molino de la Churra (Villamiel, Cáceres) ${ }^{102}$ y Ceclavín (Cáceres). ${ }^{103}$

Sin embargo, el nombre divino que podría tener una relación directa con el que nos ocupa es de origen itálico. Se trata de Salacia, que fue considerada pareja de Neptuno, como se puede desprender de las palabras de Aulo Gelio: Conprecationes deum inmortalium, quae ritu Romano fiunt, expositae sunt in libris sacerdotum populi Romani et in plerisque antiquis orationibus. In his scriptum est: Luam Saturni, Salaciam Neptuni, Horam uirini, Virites Quirini, Maiam Volcani, Heriem Iunonis, Moles Martis, Nerienemque Martis. ${ }^{104}$ En este mismo sentido habría que interpretar la expresión de Varrón Salacia Neptuni ab salo, como que el nombre de la esposa de Neptuno deriva de salum, alta mar. ${ }^{105}$ Esta forma de expresar el nombre de la deidad, citándola junto nombre de Neptuno en genitivo podría expresar una vinculación no equitativa de la diosa con el dios romano. ${ }^{106} \mathrm{En}$ este sentido, Bayet resaltaba también la costumbre mantenida entre los itálicos de dar a un dios el epíteto de otro remarcando una cierta jerarquización cultual entre ambos, como en los casos de Hercules Iouius o Venus Iouia, que denotaban una dependencia de Hércules y Venus respecto de Júpiter. Eran, sin embargo, subordinaciones muy genéricas que intentaban estructurar la gran cantidad de nombres divinos otorgando al panteón religioso un cierto orden. ${ }^{107}$

En línea con la consideración de que Neptuno y Salacia eran una pareja divina, cuando el primero fue sincretizado con Poseidón, la diosa asumió características de la griega Anfitrite, que estaba vinculada al dios heleno de las aguas, o incluso llegó a relacionarse con Tetis. ${ }^{108}$ En este orden de ideas, Pacuvio relacionaba a Salacia con el mar tempestuoso; ${ }^{109}$ Festo, al igual que Varrón, hacía derivar su nombre de la palabra salum, con el sentido de mar profundo o alta mar. ${ }^{110}$ San Agustín relacionaba la diosa con Neptuno, afirmando que, para que el dios tuviera una esposa, se le había asociado Salacia. De modo seme-

102 Rubio 1955, 297-298; AE 1956, 224; Albertos 1985, 469-470; Blázquez 1962, 189; Melena 1985, 475.

${ }^{103}$ Melena, ibid., 481-483 y 498.

104 Gell., Noct. Att., 13, 23, 2.

105 Varro, Ling., V, 72.

106 Wissowa 1902, 35; Bayet 1984, 134-35.

107 Bayet, ibid., loc.cit.

108 Wissowa 1902, 251.

109 Frg. 418. Sobre esta particularidad de Salacia, uid. Bloch 1981, 345 .

${ }^{110}$ Fest., p. 481. 
jante al de Juno, que ocupaba la parte inferior del cielo dejando la parte superior a Júpiter, Salacia ocupaba la parte inferior del mar mientras Neptuno estaba en la superficie. ${ }^{111}$ Salacia era, pues, la diosa de la parte más profunda del mar: ipse in mari Neptunus, in inferioribus etiam maris ipse Salacia. ${ }^{112}$ San Agustín precisaba, además, que ambas deidades formaban pareja: Iam utique habebat Salaciam Neptunus uxorem, quam inferiorem aquam maris esse dixerunt. ${ }^{13} \mathrm{Al}$ mismo tiempo, Agustín relacionaba a Salacia con Venilia y a ambas con el mar, afirmando con sorna que, mientras la primera era la ola que penetraba en altamar, la segunda era la ola que llegaba a la orilla. ${ }^{114}$ También Servio, en sus comentarios a la Eneida de Virgilio, vincula a Salacia con Neptuno y con el agua salada ${ }^{115}$ afirmando, además, que ambos dioses eran los padres de Tritón. ${ }^{116} \mathrm{~Pa}$ cuvio, refiriéndose a la ferocidad del mar tempestuoso, la atribuía a la crueldad de Salacia. ${ }^{117}$ La relación de la diosa con el mar fue también plasmada por Cicerón, que resaltaba su vinculación fraternal con Océano ${ }^{118} \mathrm{y}$, en el campo de la novela, por Apuleyo. ${ }^{119}$

La identificación etimológica de Salacia con la sal y el mar pudo tener su origen en una previa vinculación a Neptuno, lo que habría llevado a interpretaciones posteriores en esa dirección. ${ }^{120}$ Quizá expresaba una cualidad divina en un período anterior a su conversión en divinidad, en un proceso semejante al que sufrieron Ceres, Fides u Ops. Algunos autores interpretan así las palabras de Aulo Gelio con las que parece adjudicar un aspecto, un modo de acción específico a distintas deidades romanas, más que una

${ }^{111}$ Aug., Ciu., 4, 10, 2.

112 Ibid.., 4, 11, 2.

${ }^{113}$ Ibid., 7, 22, 1.

${ }^{114}$ Ibid., loc.cit.

115 Serv., Aen., 10, 76.

116 Ibid., 1, 144

${ }^{117}$ Pacuv., frg. 418: Hinc saevitiam Salaciae fugimus.

118 Cic., Tim.. 11 (Sic igitur ut ab his est traditum horum deorum ortus habeatur atque dicatur, ut Oceanum Salaciamque Caeli satu Terraeque conceptu generatos editoque memoremus, ex is Saturnum et Opem, deinceps Iovem atque Iunonem, reliquos, quos fratres inter se agnatosque usurpari atque appellari videmus, et eorum, ut utamur veteri verbo, prosapiam).

${ }_{119}$ Apul., Met., 4, 31: Adsunt Nerei filiae chorum canentes et Portunus caerulis barbis hispidus et gravis piscoso sinu Salacia et auriga parvulus delphinis Palaemon; iam passim maria persultantes Tritonum catervae hic concha sonaci leniter bucinat, ille serico tegmine flagrantiae solis obsistit inimi$c i$, alius sub oculis dominae speculum progerit, curru biiuges alii subnatant. Talis ad Oceanum pergentem Venerem comitatus exercitus; ibid., Apol., 31: Neptunus cum Salacia et Portuno et omni choro Nerei ab aestibus fretorum ad aestus amorum transferentur.

${ }^{120}$ Warde 1908, 186; Demicheli 2007, 73. asociación entre divinidades. ${ }^{121}$ En cualquier caso, Salacia derivaría de una estructura adjetival a partir de salum, en sintonía con los términos griegos $\sigma \alpha \dot{\lambda} \circ \varsigma$ y $\sigma \alpha \dot{\lambda} \lambda$, con el sentido de perteneciente al mar o perteneciente al agua. ${ }^{122}$

Por otra parte, Salacia también fue relacionada estrechamente con Neptuno por sus adorantes, puesto que conocemos inscripciones votivas en las que aparece la diosa y en algunas de ellas se asocia al dios del mar romano. La primera dedicación epigráfica a la diosa fue realizada en Vindobona (Viena, Austria) y apareció en 1899 en la ribera del Danubio. Fue dedicada por un soldado de la legio I Italica en el año 233 d.C. El nombre de la diosa se cita como Salacea es adorada junto a otros dioses, varios de los cuales tienen una clara vinculación con las aguas: Júpiter, Neptuno, Danuuius, Agaunus, las Ninfas y todos los dioses y diosas. ${ }^{123}$

En 1985 apareció la segunda ofrenda votiva dedicada a la diosa Salacia en Tragurium (Trogir), ciudad costera de Dalmacia. La dedicación fue hecha a Salacia Aug(usta) por Saluius Panus, liberto de Gaius. ${ }^{124}$ El nomen Saluius, representado en Dalmacia por seis inscripciones, es especialmente frecuente en la Italia Septentrional, mientras que el cognomen Panus sólo está representado por una inscripción procedente de la Galia Narbonense. La desaparición de los praenomina en la segunda mitad del s. I d. C. reafirmaría su más probable cronología, a finales del s. II o principios del III d. C. ${ }^{125}$ Para Demicheli, lo más probable es que este individuo fuera un extranjero que viajó hacia Tragurium o Salona, que hizo el voto a Salacia como esposa de Neptuno, en agradecimiento por su buen viaje por mar una vez realizado o, por el contrario, solicitando una feliz travesía antes de su partida. Según el mismo autor, también es posible que la ofrenda fuera realizada a Venus Salacia por alguna razón relacionada con la lujuria (salax) o que, como en los votos a Venus Pelagia, se hubiera relacionado también con las circunstancias del viaje por mar. $^{126}$

Recientemente, ha sido registrado en la capital dacia de Sarmizegetusa un tercer altar dedicado a Neptuno y Salacia, en el que estos dioses son venerados junto a Esculapio, Salus, Epiona, Venus y los Cupidines, por Quintus Axius Aelianus, cuando era

${ }^{121}$ Gell., Noct. Att. XIII, 23, 1. Dumézil 2000, 399; Warde 2008, 145 ss. y 426-428.

${ }^{122}$ Trumper 2004, 62-63.

${ }^{123}$ CIL III, 14359; ILS 2968. Demicheli 2007, 77, fig. 5.

124 Demicheli 2007, 71.

125 Ibid., 71-72.

${ }^{126}$ Demicheli 2007, 78. Sobre Salacia como dea meretricum, Serv., Aen., 1, 720. Wissowa 1902, 251. 
procutaror en la provincia durante el gobierno de Maximino Tracio. ${ }^{127}$ La diosa Salacia aparece, por tanto, de nuevo vinculada a Neptuno y junto a otras deidades curativas y relacionadas con las aguas, aunque no todas estaban vinculadas específicamente con el ámbito marítimo.

El dedicante del ara votiva había ocupado varios cargos en distintas provincias durante la época de los Severos, como el de curator ad populos uiarum Traianae et Aureliae Aeclanensis, procurator ad alimenta para Apulia, Calabria, Lucania y Bruttium, en la Península Itálica. Posteriormente fue procurator rationum priuatarum o administrador de los dominios privados del emperador en Mauritania Cesariana durante el gobierno de Severo Alejandro, cargo que también había ejercido en Belgica y las dos Germanias. Fue, seguidamente, procurator de la provincia Dacia Apulensis, es decir, gestor de uno de los distritos tributarios en que se dividía la provincia de Dacia, siendo posteriormente patrono de la colonia Sarmizegetusa, la capital provincial, que se hallaba en esa misma demarcación. ${ }^{128}$ En Dacia, Axius Aelianus había erigido otros monumentos votivos a distintas deidades, como a Fortuna Redux, los Lares Viales y Roma Aeterna en la Colonia Apulensis (Karlsbourg); ${ }^{129}$ en Sarmizegetusa había honrado a Mitra, al dios romano-céltico Mars Camulus y a Mercurio junto a su paredra céltica Rosmerta. ${ }^{130}$ También la Tríada Capitolina y los dioses galos Apolo Grannus y Sirona recibieron ofrendas del procurador en territorio dácico ${ }^{131}$.

A pesar de las dedicaciones a deidades originarias de diferentes ámbitos, el hecho de que Axius Aelianus se incluya en la tribu Palatina indicaría que sería de origen itálico, lo que parece más probable si tenemos en cuenta sus primeros cargos, ejercidos en las regiones centrales de la Península Itálica y al sur de la misma. Aelianus podría haber sido originario de la capital del imperio o de Pouzzoles, cuyos ciudadanos se incluían en la tribu Palatina. ${ }^{132}$

A partir de estos datos, hemos de tener en cuenta que en la ciudad lusitana de Salacia $^{133}$ (Alcacer do $\mathrm{Sal}$ ), se acuñaron desde época prelatina monedas en

\footnotetext{
${ }^{127}$ Piso 1998, 266-267, n ${ }^{\circ}$ 14. Sobre las inscripciones relativas a Axius Aelianus, ibid., 265, n. 46.

${ }^{128}$ CIL III, 1456; ILS 1371; Renier 1864, 315-318; Jacques 1983, 232-233.

${ }^{129}$ Ackner; Müller 1864, 91, n 427; Renier 1864, 314.

${ }^{130}$ Piso 1998, 264-265, $\mathrm{n}^{\circ} 13$.

${ }^{131}$ Ackner; Müller 1864, 15, nº 60 y 48, no 203.

132 Jacques 1983, 233.

${ }^{133}$ Mela, III, 8; Plin., nat., 4, 116-117, quien la denomina urbs imperatoria; Itin. Ant., 417, 4 y 426, 4; Ravenn., 316, 14; como municipio, CIL II, 32.
}

cuyo anverso se representó la cabeza de Hércules en el anverso, motivo que se continuó usando en época plenamente romana, ya con busto barbado de Neptuno, pero manteniendo las iconografías anteriores en los reversos de delfines, ahora añadiendo la leyenda IMP SAL en el centro de las imágenes. ${ }^{134}$ Estas deberían datarse en la segunda mitad del s. I a. C. ${ }^{135}$ Aunque estos datos puedan parecer anecdóticos, lo cierto es que Salacia fue, junto a la Bética Carteia, la única ciudad de Hispania que acuñó moneda con la representación de Neptuno. ${ }^{136}$

La iconografía de Hércules podría haber representado al Melkart púnico, también dios del mar, de la navegación, protector de los comerciantes y marineros, que aparecía en las monedas púnicas cabalgando sobre un caballo marino y, como en Gades, se asociaba en las mismas a delfines y atunes y, posteriormente, vendría su sustitución por Neptuno a fines de la República. ${ }^{137}$

Hemos de tener en cuenta, por tanto, un contexto religioso en el que la adoración a una divinidad masculina romana vinculada al mar, es decir, el culto a Neptuno, era muy probable en el ámbito minero de Cartago Noua. Pero, además, el substrato cultural de este territorio incluía todo un conjunto de creencias religiosas púnicas, algunas de ellas relacionadas con deidades marinas. Las principales eran Melqart, que los griegos interpretaron en diversas ocasiones como Poseidón ${ }^{138}$ y los romanos como Neptuno, y Koushar, al que los griegos compararon con Tritón. ${ }^{139}$

Al Poseidón púnico le fueron erigidos santuarios en diversos puntos de la costa occidental mediterránea, como en el Cabo Soloeis, situado al occidente de las Columnas de Hércules según consta en el Periplo de Hannón. ${ }^{140}$ También Amílcar durante la Primera Guerra Púnica, según Diodoro, llevó a cabo sacrificios a Poseidón en la costa siciliana. ${ }^{141}$ Según Herodoto, los libios que habitaban a orillas del lago Tritónide ofrecían sacrificios sobre todo a Atenea y,

\footnotetext{
${ }^{134}$ Marqués de Faria 1989, 93; Mantas 1990, 174; Burnett; Amandry; Ripollès 1998, 7; Amela 2004b, 245 ss.

${ }^{135}$ Burnett; Amandry; Ripollés 1998, S-51A-B; Ripollés; Abascal 2000, 251; Amela 2004a, 108 ss.; id. 2004b, 247.

136 Amela 2004a, 109.

${ }^{137}$ García-Bellido 1990, 378.

${ }^{138}$ Fantar 1993, t. 2, 243, 285-286 y 290.

${ }^{139}$ Fantar 1993, t. 2, 243 y 288-291.

${ }^{140}$ Periplo de Hannón, fr. II-III (Garzón 1987, 81). Dicho periplo se habría escrito entre los años 470-400 (Garzón, ibid., 82). Sobre la situación de Soloeis, podría corresponder a Cap Cantín (ibid., 83). Para Garzón, el dios debió ser el púnico Baal Rosh, también de carácter marino (ibid., 83, n. 7).

${ }^{141}$ D.S., $11,21,4$.
} 
en segundo lugar, a Tritón y Poseidón ${ }^{142}$. Para Herodoto, los griegos conocieron a Poseidón por los libios, quienes habían adorado a Poseidón desde tiempos inmemoriales. ${ }^{143}$ Independientemente de la veracidad o falsedad de esta afirmación, lo que parece evidente es el gran arraigo de una divinidad marina semejante al dios griego en territorio púnico. ${ }^{144}$

Por otra parte, conocemos diversas representaciones iconográficas púnicas que podrían ser deidades marinas, por estar asociadas a elementos marítimos como el tridente o peces en Ibiza, Utica y Carthago o por aparecer cabalgando a un hipocampo en Kerkouane. Según Fantar, podrían ser imágenes del Poseidón púnico, aunque la cuestión no está resuelta. ${ }^{145}$

Algo parecido ocurre con la deidad púnica que los griegos relacionaron con Tritón. ${ }^{146}$ Heródoto contaba que Jasón fue desviado por los vientos cuando intentaba circunnavegar la Península del Peloponeso para llegar a Delfos y fue arrastrado hasta Libia, quedando embarrancado en el lago Tritónide. Allí se le apareció Tritón quien, tras pedir a Jasón un trípode que luego colocó en su propio santuario, llevó a cabo un oráculo y les ayudó a retomar la dirección adecuada. Heródoto relataba, además, que Tritón era una de las deidades a la que más sacrificios se dedicaban y, por otra parte, era quien fijaba los límites entre algunos pueblos de esa región. ${ }^{147}$ Esta sería la divinidad ictiomorfa que aparece representada en escarabeos, tumbas y elementos de adorno hallados en distintos lugares del mundo púnico. ${ }^{148}$

La importancia de estas deidades se hace patente en el juramento de Aníbal que sella el pacto de mutua protección entre los cartagineses y Filipo $\mathrm{V}$ de Macedonia, puesto que la tercera tríada divina a la que se hace testigo de dicho acuerdo está formada por Ares, Tritón y Poseidón. ${ }^{149}$

\footnotetext{
$1424,188$.

143 2, 50, 1-3. Lipiñski 1995, 392.

${ }^{144}$ Cadotte 2007, 53.

${ }^{145}$ Fantar 1993, t. 2, 286-288. El hipocampo también aparece frecuentemente en la iconografía etrusca, aunque es más raro que sea cabalgado por un personaje. Su origen habría venido del área Jonia o el Atica. En el mundo griego es Poseidón quien aparece montando a este animal (Hus 1955, 78 ss.). En cualquier caso, en el Kylix de Cerveteri, datable en el s. VI, se ven claramente las influencias griegas en la representación del dios montando una cabalgadura con cola de pez (Rodríguez López 2006, 7, fig. 2) y también en otros soportes cerámicos en los que aparecen tritones e hipocampos (ibid., 10 ss.).

${ }_{146}$ Pol., Hist., 7, 9, 2.

147 4, 179. Según Fantar, el lugar estaría al sureste de Túnez, en el Golfo de Gabès. Sobre las otras deidades destinatarias de los sacrificios, uid. supra.

${ }^{148}$ Fantar 1993, t.2, 289-290.

${ }^{149}$ Pol., Hist., 7, 9, 2. Cadotte 2007, 310.
}

En la región de Hadrumetum y Thapsus también se documenta la importancia del dios Neptuno, teniendo en cuenta las acuñaciones monetarias. Aparece en ellas un dios barbudo vestido con un pallium y con tridente. En el reverso aparece una deidad femenina con cetro, que quizá se podría identificar con Astarté. ${ }^{150}$

En definitiva, el substrato cultural púnico provocó que el culto a deidades masculinas relacionadas con el mar penetraran con relativa fluidez en el sureste de la Península Ibérica durante todo el siglo in a. C. Por ello, el culto al romano Neptuno, cuyo perfil se había fundido en parte con el de Poseidón desde el s. IV a. C., ${ }^{151}$ encontró un ambiente religioso y simbólico apropiado para su difusión. Por otra parte, hemos de recordar que Neptuno fue la principal deidad bajo cuya protección se produjo la conquista de la ciudad de Carthago Noua por los romanos. El dios se apareció en sueños a Escipión, según Polibio, para prometerle su ayuda y, posteriormente, provocó la bajada de las aguas en el lago inmediato a la ciudad, lo que facilitó el avance rápido de las tropas romanas hacia las zonas más desguarnecidas de las murallas y, por tanto, su asalto final ${ }^{152}$. Livio lo resume afirmando que Escipión ordenó a sus soldados seguir a Neptuno como guía de su avance a través de la laguna. ${ }^{153}$

Tenemos un ejemplo de la difusión de la simbología religiosa relacionada con el dios romano en el monte de Sta. Lucía, según nos cuenta Cerezuela, quien vio algunos enlucidos en las paredes con figuras «como de medio hombre y medio pescado, otras a modo de sátiro, y otras como de Neptuno». ${ }^{154}$ Por otra parte, el nominativo plural Roscies que, como se vio arriba, es característico del territorio itálico induce a pensar que Salaecus es originario del mismo ámbito. Además, el lugar donde fue hallada la inscripción, cerca del mar y en un contexto económico, la explotación minera de la plata, que conllevaba largas travesías por mar para transportar el metal, hacen preferible la hipótesis de que Salaecus fuera un

${ }^{150}$ Cadotte 2007, 310 ss. No obstante, en otras monedas aparece la misma deidad con la cabeza radiada, por lo que podría tratarse de una adaptación de Neptuno a una deidad local que tendría, además, caracter agrario. Sería, por tanto, semejante al Ïióåáäùí êáñoiäüôçò de Thapsus, que tendría un apelativo equivalente al latino frugifer del dios Saeculum Frugiferum de las monedas de Clodio Albino, originario de Hadrumetum (ibid., 315).

${ }^{151}$ Rodríguez López 2006, 3.

${ }^{152}$ Pol., Hist., 10, 11, 7; 10, 14, 7-12.

${ }^{153}$ Liv., 26, 45, 9. Sobre las circunstancias de esta conquista y la bajada de las aguas, uid., Walker et al. 1988, 477 ss. y Hoyos 1992, 124 ss.; id. 2007, 112-113 para quien, siguiendo a Tito Livio, la clave fue la participación del viento.

${ }^{154}$ Rubio Paredes 1978, 66-67. 
apelativo del dios Neptuno a su alternativa, a saber: que se tratara de un epíteto tópico referente a una divinidad local de alguna ciudad mediterránea o del interior de Hispania. A pesar de que esta hipótesis también sería plausible, dado el cuantioso movimiento de grupos de trabajadores hacia las minas, parece más lógico pensar en una deidad como Neptuno con un apelativo relacionado con el mar y vinculado a su pareja Salacia, en un ámbito como el de Carthago Noua, con numerosos inmigrantes itálicos.

\section{BIBLIOGRAFÍA}

Abascal Palazón, J. M., Los nombres personales en las inscripciones latinas de Hispania, Murcia, 1994.

Abascal Palazón, J. M., «Programas epigráficos augusteos en Hispania», Anales de Arqueología Cordobesa 7, 1996, pp. 45-82.

Abascal Palazón, J. M., Gimeno, H., Epigrafía Hispánica, Madrid, 2000.

Abascal Palazón, J. M.; Ramallo, S., La ciudad de Carthago Nova: La documentación epigráfica. Murcia, 1997.

Ackner, M. J.; Müller, F., Die Romischen Inschriften in Dacien. Wien, 1865.

Albertos, M. L., «A propósito de algunas divinidades lusitanas (Arantius Ocelaecus, Arantia Ocelaeca) y el elemento ocelum», Symbolae Ludovico Mitxelena septuagenario oblatae. Vitoria, 1985, pp. 469-494.

Alves, F. M., Memorias archeológico-históricas do distrito de Bragança. Porto, 1909.

Alves, F. M., Apontamentos arqueológicos. Chaves, 1931.

Amante, M.; Martín, M.; Pérez Bonet, M. A.; González Fernández, R.; Martínez Villa, M. A., «El sacellum dedicado a Iuppiter Stator en Cartagena», Antigüedad y Cristianismo (Murcia) 12, 2005, pp. 533-562.

Amela, L., «Una cuestión metodológica: la localización de las cecas en el período final de la república romana. El caso de RRC 477», Documenta \& Instrumenta 2, 2004a, pp. 99-119.

Amela, L., «Sobre Salacia y otras apreciaciones acerca de algunas cecas de la Hispania occidental», Revista Portuguesa de Arqueologia 7.2, 2004b, pp. 243-264.

Antolinos, J.A.; Noguera, J.A.; Soler, B., «Poblamiento y explotación minero-metalúrgica en el distrito minero de Carthago Noua», J. M. Noguera Celdrán (ed.), Poblamiento rural romano en el
Sureste de Hispania, 15 años después, Murcia, 2010, pp. 167-231.

Bakkum, G.C.L.M., «The Second-declension nominative plural in -eis, -es, -is and the first declension nominative plural in -as», en J. Herman (ed.), Linguistic studies on Latin. Selected papers from the $6^{\text {th }}$ international colloquium on latin linguistic (Budapest, 23-27 march 1991), AmsterdamPhiladelphia, 1994, pp. 19-39.

Barreda Pascual, A., «El valor de la onomástica en el estudio de los nominativos plurales temáticos en -eis como nominativos de influencia osca», $\mathrm{Fa}$ ventia 17/1, 1995, pp. 49-65.

Bayet, J., La religión romana. Historia política y psicológica. Madrid, 1984.

Beltrán, F.; Díaz, B., «Altares con teónimos hispano-célticos de la Meseta norte», en M. Hainzmann (ed.), Auf den Spuren keltischer Götterverehrung, Akten des 5 F.E.R.C.A.N., Wien, 2007, pp. 29-56.

Beltrán, J. A., Introducción a la morfología latina, Zaragoza, 1999.

Bémont, C., «Observations sur quelques divinités gallo-romaines: les rapports entre la Bretagne et le continent», $E C$ 18, 1981, pp. 65-88.

Birley, E., «The deities of Roman Britain», ANRW 18.1, 1986, pp. 6-112.

Blázquez, J. M., Religiones primitivas de Hispania I. Fuentes literarias y epigráficas. Madrid, 1962.

Bloch, R., «Quelques remarques sur Poseidon, Neptune et Nethuns», Comptes-rendus. Académie des inscriptions et belles-lettres 125, n. 2, 1981, pp. 341-352.

Brunt, P. A., Italian Manpower, 225 B.C.- A.D. 14. Oxford, 1971.

Burnett, A.; Amandry M.; Ripollés, P. P., Roman Provincial Coinage. Volume I. From the death of Caesar to the death of Vitellius (44 B.C.-A.D. 69). Part I: Introduction and Catalogue. Supplement I, London, 1998 (=RPC).

Cadotte, A., La romanisation des dieux. L'interpretatio romana en Afrique du Nord sous le HautEmpire. Leiden, 2007.

Carnoy, A., Le latin d'Espagne d'après les inscriptions, Bruxelles, 1906.

Coleman, R., «Dialectal variation in republican latin, with special reference to Praenestine», $P C P h S$, 36, 1990, pp. 1-25,

Conway, S., The italic Dialects, Darmstadt, 1967.

Cumont, F., Las religiones orientales y el paganismo romano. Madrid, 1987 [ $1^{a}$ ed. 1929]

Curchin, L., «Place names of the Ebro valley: their linguistic origins», Palaeohispanica 8, 2008, pp. 13-33. 
Dauzat, A. ; Deslandes, G. ; Rostaing, Ch., Dictionaire étymologique des noms de rivières et de montagnes en France. Paris, 1978.

De Hoz, J., «Hidronimia antigua europea en la Península Ibérica», Emerita 31, 1963, pp. 227-242.

Demicheli, D., «Altar of the goddess Salacia from Trogir», Opusc. Archaeol. 31, 2007, pp. 69-80.

Devoto, G., Storia della lingua di Roma, Bologna, 1940.

Díaz Ariño, B., Epigrafía latina republicana de Hispania, Barcelona, 2008.

Domergue, C., Les mines de la Penínsule Ibérique dans l'antiquité romaine. Roma, 1990.

Domergue, C., «Lingote de plomo romano», Bocamina: Patrimonio minero de la Región de Murcia.Catálogo de la exposición, Murcia 8 de septiembre - 6 de noviembre de 2005, Murcia, 2005, ficha 69, p. 190.

Dumézil, G., La religion romaine archaïque. Paris, 2000 ( $1^{\text {a }}$ edición, 1974).

Encarnação, J., «Omissão dos teónimos em inscrições votivas», Veleia (Actas del IV Coloquio sobre Lenguas y Culturas Paleohispánicas), 2-3, 19851986, pp. 305-310.

Ernout, A., «Le parler de Préneste d'après les inscriptions», Mémoires de la Societé de Lingüistique de Paris 13, 1905-1906, pp. 293-349.

Ernout, A., Morphologie historique du latin, Paris, $1953^{3}$.

Ernout, A., Recueil de textes latins archaïques, Paris, $1966^{9}$

Fantar, M. H., Carthage. Approche d'une civilisation. Tunisie, 1993.

Fatás, G., Contrebia Belaisca. II Tabula Contrebiensis, Zaragoza, 1980.

Faria Marqués de, A. J., «A numária de Cantnipo», Conimbriga 28, 1989, pp. 71-99.

Fernández Díaz, A., La villa romana de Portmán: programa decorativo-ornamental y otros elementos para su estudio, Murcia, 1999.

Fernández Díaz, A., «Portmán: de villa industrial a villa de recreo», Mastia 2, 2003, pp. 65-107.

Fernández Díaz, A., La pintura mural romana de Carthago Noua. Evolución del programa pictórico a través de los estilos, talleres y otras técnicas decorativas, Vol. 1, Murcia, 2008, pp. 355-414.

Fontes Lourenço, A., «Culto ao deus Larouco, Júpiter e Ategina», Rev. Guim. extraord. Actas do sem. Arq. do NW peninsular. Vol III, 1980, pp. 5-25.

García Alonso, J. L., «On the celticity of some hispanic place names», EC 29, 1992, pp. 191-201.

García Alonso, J. L., La Península Ibérica en la Geografía de Claudio Ptolomeo. Vitoria, 2003.
García-Bellido, M. P., «Iconografía fenicio-púnica en las monedas repúblicanas de la Bética», Zephyrus 43, 1990, 371-383

Garnsey, P., «Independent Freedmen and the Economy of Roman Italy under the Principate», Klio 63, 1981, pp. 359-371.

Garzón, J., «Hannón de Cartago, periplo. Cod. Palat. 398 fol. 55r-56r», Memorias de Historia Antigua 8, 1987, pp. 81-86.

Gimeno, H., «Nuevos datos para la colonia Salaria», Lucentum 23-24, 2004-2005, pp. 181-184.

González Fernández, R., «El nominativo singular en $-i$ de los gentilicios latinos en la epigrafía del área de Cartago Noua. El caso particular de la gens Aquinia», Verdolay 7, 1995, pp. 351-356.

Haley, E. W., Foreigners in roman imperial Spain: investigations of geographical mobility in the spanish provinces of the roman empire, 30 B.C.-A.D. 284. Columbia, 1986.

Hogan, E., Onomasticon Goedelicum locorum et tribuum Hiberniae et Scotiae. An index, with identifications, to the gaelic names of places and tribes. London, 1910.

Hoyos, B. D., «Sluice-Gates or Neptune at New Carthage, 209 B.C.? », Historia: Zeitschrift für Alte Geschichte 41, n. 1, 1992, pp. 124-128.

Hoyos, B. D., Truceless war. Carthage's fight for survival, 241 to 237 B.C. Leiden, 2007.

Hus, A.; «Sculpture étrusque archaïque : le cavalier marin de la Villa Giulia», Mélanges d'archéologie et d'histoire 67/1, 1955, pp. 69-126.

Jacques, F., Les curateurs des cités dans l'Occident romain de Trajan à Gallien. Paris, 1983.

Jiménez Zamudio, R., «Los nominativos plurales latinos en -es, -is, -eis y los nominativos plurales temáticos del i-e. postanatolio», Actas del II Congreso Andaluz, Málaga, 1988a, vol. 1, pp. 105110.

Jiménez Zamudio, R., «Contribución al estudio del plural de la declinación temática latina», Emerita 56, 1988b, pp. 121-126 (se trata del mismo texto que el anterior).

Kent, R. G., «Dissimilative writing for ii and iii in Latin», Transactions and Proceedings of the American Philological Association, vol. 43, 1912, pp. 35-56.

Koch, M., «Las «grandes familias» en la epigrafía de Carthago Nova», I Congreso Peninsular de Historia Antigua, Santiago de Compostela 1986, Santiago, 1988, vol. 2, pp. 403-407

Koch, M., Die Turulli und Neukarthago, Navicula Tubigensis, Studia in honorem Antonii Tovar, Leiden, 1994, Tübingen, 1984, pp. 233-246. 
Lancel, S., Hannibal. Oxford, 1999.

Lara Vives, G., López Seguí, E. «La Huerta del Paturro (Cartagena, Murcia): Una villa romana en la bahía de Portmán», J. M. Noguera Celdrán (ed. ), Poblamiento rural romano en el Sureste de Hispania, 15 años después, Murcia, 2010, pp. 233254.

Lillo Carpio, P. A., «La capsella de plata procedente de Portman, La Unión (Murcia) », Anales de Prehistoria y Arqueología 1, 1985, pp. 123-127;

Liou, B., «Un lingot de plomb romain nouvellement entrè au Musée d'Istres», Bulletin des Amis du Vieil Istres, 1991, pp. 15-19.

Lipiñski, E., Dictionnaire de la Civilisation Phénicienne et Punique, Turnhout, 1992.

Lipiñski, E., Dieux et déesses de l'univers phénicien et punique. Leuven, 1995.

López Melero, R.; Sánchez Abal, J. L.; García Jiménez, S., «El bronce de Alcántara. Una deditio del 104 a.C. », Gerión 2, 1984, pp. 265-323.

López Pardo, F., «Los enclaves fenicios en el Africa noroccidental: del modelo de las escalas náuticas al de colonización con implicaciones productivas», Gerion 14, 1996, 251-288.

Mantas, V. G., «As cidades marítimas de Lusitânia». Dans Les villes de Lusitanie romaine. Hiérarchies et territoires. Paris, 1990, pp. 149-205.

Marín Díaz, A., Emigración, colonización y municipalización en la Hispania Republicana, Granada, 1988.

Mariner, S., «Il bronzo de Contrebia: studio linguistico», Cuadernos de Trabajo de la Escuela Española de Historia y Arqueología en Roma 15, 1981, pp. 67-94.

Martín Camino, M.; Pérez Bonet, M. A.; González Fernández, R., «Un templo suburbano consagrado a Iuppiter Stator en Carthago Noua», Revista de arqueología, $\mathrm{n}^{\circ} 188,1996$, pp. 26-35.

Melena, J. L., «Salama, Jálama y la epigrafía latina del antiguo corregimiento», Symbolae Ludovico Mitxelena septuagenario oblatae. Pamplona, 1985, pp. 475-530.

Méndez Ortiz, R, «Informe de la campaña de excavaciones en la villa romana del Paturro, 19851986. Bahía de Portmán. Cartagena», Memorias de Arqueología 2, Murcia, 1991, pp. 225-233.

Méndez Ortiz, R, «Villa del Paturro (Cartagena)», Excavaciones y prospecciones arqueológicas, Murcia, 1987, pp. 264-271.

Molina Vidal, J., La dinamica comercial romana entre Italia e Hispania Citerior. Alicante, 1997.

Monteil, P., Morphologie historique du latin, Paris, $1953^{3}$.
Noguera Celdrán, J. M., «Una cabeza de Sátiro de la villa romana de la Huerta del Paturro (PortmánMurcia)», Anales de prehistoria y arqueología 56, 1989, pp. 155-160.

Noguera Celdrán, J. M., «Carthago Nova: una metrópoli hispana del Mediterráneo occidental», en J. M. Abascal, J. M. Noguera y F. J. Navarro (eds.), Cartagena romana: historia y epigrafía, Murcia, 2002, pp. 49-87.

Olivares Pedreño, J. C., Los dioses de la Hispania Céltica. Madrid, 2002.

Olivares Pedreño, J. C., «Reflexiones sobre las ofrendas votivas a dioses indígenas en Hispania: ámbitos de culto y movimientos de población», $V e$ leia 20, 2003, pp. 297-313.

Olivares Pedreño, J. C., «Hipótesis sobre el culto al dios Cossue en El Bierzo (León): explotaciones mineras y migraciones», Palaeohispanica 7, 2007, pp. 143-160.

Ouazghari, A. El, El mundo indígena y Roma en el Marruecos antiguo: la religión durante los períodos prerromano y romano. Granada, 2005.

Pena, M. J., «Algunos rasgos dialectales del latín de Hispania», Faventia 12 13, Fasc. 1-2, 1990 1991, pp. 389-400.

Pena, M. J., «CLE republicanos: texto y contexto», Asta ac pellege, Madrid, 2002, pp. 47-62;

Pena, M. J.; «Consideraciones sobre epigrafía republicana de la Citerior: el caso de Carthago Nova», en J. Uroz, J.M. Noguera y F. Coarelli (eds.): Iberia e Italia: modelos romanos de integración territorial. Murcia, 2008, pp. 687-710..

Peralta, E., Los Cántabros antes de Roma. Madrid, 2000.

Piso, I., «Inschriften von Prokuratoren aus Sarmizegetusa (II) », ZPE 120, 1998, pp. 253-271.

Ramallo, S. F., «Pavimentos de opus signinum en el Conventus Carthaginiensis», Pyrenae, 15-16, 1979-80, pp. 287-317.

Ramallo, S. F., Mosaicos romanos de Carthago Noua (Hispania Citerior), Murcia, 1985.

Ramallo, S. F., «Inscripciones sobre pavimentos de época republicana en la Hispania romana», Epigrafía Hispánica de época romano-republicana, Zaragoza, 1986, pp. 183-187.

Ramallo, S.; Berrocal, M.C., «Minería púnica y romana en el sureste peninsular: el foco de Carthago Noua», D. Vaquerizo Gil (coord.), Minería y metalurgia en la España prerromana y romana, Córdoba, 1994, 79-146.

Ramallo, S.; Ruiz, E., «Un edículo republicano dedicado a Atargatis en Carthago Nova», AEspA, 1994, pp. 79-112. 
Ramallo, S.; Fernández, A.; Madrid, M. J.; Ruiz, E., «Carthago Nova en los dos últimos siglos de la República: una aproximación desde el registro arqueológico», en J. Uroz, J.M. Noguera y F. Coarelli (eds.), Iberia e Italia: modelos romanos de integración territorial. Murcia, 2008, pp. 573604.

Renier, L., «Inscriptions relatives au procurateur impérial Q. Axius Aelianus», Revue Archéologique 10, 1864, pp. 314-321.

Rickard, A., «The Mining of the Romans in Spain», JRS, 18, 1928, pp. 129-143.

Ripollés, P.P.; Abascal, J.M., Monedas Hispánicas. Real Academia de la Historia. Catálogo del Gabinete de Antigüedades. Madrid, 2000.

Rodríguez López, M. I., «Dioses y demonios marinos en el mundo etrusco: creencias, espacios, significación e iconografía», Akros 5, 2006, pp. 117.

Rodríguez Neila, J. F.; González Román, C.; Mangas, J.; Orejas, A., El trabajo en la Hispania romana, Madrid, 1999.

Roussel, P.; Launey, M., Inscriptions de Délos (Décrets et dédicaces postérieures à 166 avant $J C)$, Paris, 1937.

Rubio Paredes, J.M., Fulgencio de Cerezuela. Antigüedades de Cartagena, Murcia, 1978.

Rubio, J., «Nuevas inscripciones romanas», Zephyrus 6, 1955, pp. 295-299.

Salas, J.; Esteban J.; Rueda, G., «Bandia Apolosegus, una divinidad de culto local en la zona de Brozas, Cáceres (Nuevas aportaciones epigráficas) », HAnt. 13, 1986-1989, pp. 9-17.

Santos, J.; Emborujo A.; Ortiz de Urbina E., «Recons- trucción paleogeográfica de autrigones, caristios y várdulos», Complutum 2, 1992, pp. 449-467.

Scullard, H.H., Scipio Africanus in the Second Punic War. Cambridge, 1929.

Solin, H.; Salomies, O., Repertorium nominum gentilium et cognominum Latinorum, Hildesheim, 1988.

Sommer, F., Handbuch der lateinischen Laut- und Formenlehre, Heidelberg, 1914.

Syme, R., «Senators, Tribes and Towns», Historia XIII /1, 1964, pp. 105-125.

Tranoy, A., La Galice romaine. Recherches sur le nord-ouest de la Péninsule Iberique dans l'antiquité. Paris, 1981.

Trumper, J.B., «Greek Naiads amongst the Brettii, Oscan Naiads in Greek colonies: Calabrian Hidronymy, a long term perspective and intra-mediterranean comparisons», en Adrionian: Visions, Echoes, Maps and Routes, Thessaloniki. Ziti 2004, pp. 39-89.

Vasconcelos, J.L., «Por Tras-os-Montes», Arq. Port. 22, 1917, pp. 16-17.

Vine, B., Studies in Archaic Latin Inscriptions, Innsbruck, 1993.

Walker, M.J.; Pujante A. L.; Lillo A.; Lillo, M., «On Polybius X 10,12 f.: The Capture of New Carthage», Historia: Zeitschrift für Alte Geschichte, 37, n. 4, 1988, pp. 477-480.

Warde, W., The Roman Festivals of the Period of the Republic. London, 1908.

Warde, W., The religious experience of the roman people from the earliest times to the age of $\mathrm{Au}$ gustus. 2008 [1911].

Wissowa, G., Religion und Kultus der Römer. München, 1902.

Recibido el 10-02-10

Aceptado el 09-09-10 